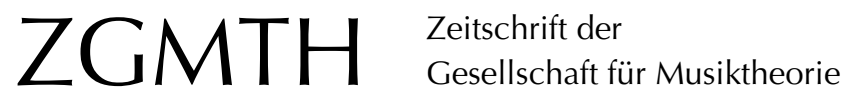

Helbing, Volker (2010): Zyklizität und Drama(turgie) in Scelsis viertem Streichquartett. ZGMTH 7/3, 267-309. https://doi.org/10.31751/575

(c) 2010 Volker Helbing

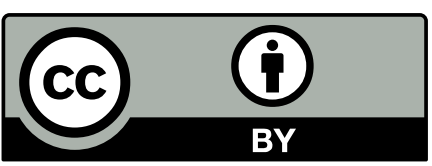

Dieser Text erscheint im Open Access und ist lizenziert unter einer Creative Commons Namensnennung 4.0 International Lizenz.

This is an open access article licensed under a

Creative Commons Attribution 4.0 International License.

veröffentlicht / first published: 22/12/2010

zuletzt geändert / last updated: 07/05/2011 


\title{
Zyklizität und Drama(turgie) in Scelsis viertem Streichquartett
}

\author{
Volker Helbing
}

Die besonders stark ausgeprägte Prozessualität des vierten Streichquartetts Giacinto Scelsis ist der Grund, warum in diesem Beitrag zwei Aspekte der Formbildung im Mittelpunkt stehen. Es sind dies die bis zu einem gewissen Grade regelmäßige, ja zum Teil fast wörtliche Wiederkehr bestimmter Gesten, satztechnischer Konstellationen, Klänge (auch tonaler) oder Entwicklungszüge und die Orientierung an Bauprinzipien des klassischen Dramas, was das gezielte `Vorführen von Stationen, durch das im dramatischen Verlauf entscheidende Ereignisse spannungsvoll ,vorbereitet`, Höhepunkte plastisch herausgearbeitet oder formale Zäsuren hervorgehoben werden, miteinschließt. Beide Aspekte - hier `Zyklizitätı und `Dramaturgie` genannt - hängen aufs Engste zusammen: Zum einen gehört `Wiederholung` zu den elementarsten Steigerungsprinzipien überhaupt und zum anderen wird erst an der veränderten Wiederkehr (von Formkomponenten ebenso wie von ganzen Formsegmenten) ein dramatischer Ablauf erfahrbar.

Es fällt schwer, sich der Sogwirkung zu entziehen, die das einsätzige vierte Quartett Giacinto Scelsis zunächst noch eher zurückhaltend und immer wieder unterbrochen, ab der zweiten Hälfte dann aber nahezu durchgängig ausübt. ${ }^{1}$ Die Ursachen für diesen bei einem Werk Scelsis eher seltenen Befund scheinen auf der Hand zu liegen: der mikrotonale Anstieg von einem vierteltönig erniedrigten $c$ bis $h$ als diastematischer Grundriss, die Verbreiterung der Einzelstimme zum vibrierenden und oszillierenden, pausenlos ineinander verflochtenen Stimmenstrang sowie eine zunehmend massive `Orchestrierung`. Und doch ist damit nicht erklärt, warum das Stück alles andere ist als eine Steigerungsetüde, warum das Interesse (auch beim wiederholten Hören) anhält, warum also am Ende nicht die Erschöpfung überwiegt, sondern der Eindruck, einem ‘geschlossenen` Drama beigewohnt zu haben, das demnach eine wie auch immer geartete `Form` besitzen muss.

Der folgende Beitrag nähert sich diesen Fragen von zwei Beobachtungen her: Einerseits arbeitet auch diese Musik, so kontinuierlich und bis ins Kleinste nuanciert sie ist, mit den Mitteln der Wiederholung und der Variantenbildung, andererseits weist sie - bei aller klanglichen Avanciertheit - eine klare, ja traditionelle musikalische Dramaturgie auf, d.h. sie orientiert sich ebenso an Bauprinzipien des klassischen Dramas, wie sie auch

1 Tristan Murail, der für Scelsi insgesamt einen Verzicht auf prozesshafte Gestaltungen konstatiert (und damit eine deutliche Differenz zur eigenen Formkonzeption), zeigt sich von einigen einsätzigen Werken wie dem vierten Quartett und Anahit aufgrund ihrer »strengeren Formauffassung " stärker angezogen und spricht er von der »einzigartigen und unwiderstehlichen Geste», als die sich »etwa der langsame und eindeutige Aufwärtstrend des vierten Streichquartetts darstellt [...]« (1999, 63). 
zentrale Stationen der Form svorführtı. Beide Aspekte hängen aufs Engste zusammen, insofern Wiederholung zu den elementarsten Steigerungsprinzipien gehört und an der veränderten Wiederkehr (von Formkomponenten ebenso wie von ganzen Formsegmenten) der dramatische Ablauf überhaupt erst erfahrbar wird.

Es ist ein fait accompli der Forschung, Tendenzen zu Regelmaß, Periodizität und Gliederung bei Scelsi seien durch ein übergreifendes Streben nach Kontinuität und Prozesshaftigkeit relativiert. ${ }^{2}$ Dementsprechend werden wörtliche Übernahmen vor allem unter dem Aspekt der Rückläufigkeit diskutiert. ${ }^{3}$ Dass die Gestaltung des vierten Streichquartetts hierzu im Widerspruch steht, ist offensichtlich. (Die Klärung der Frage, ob das Werk in dieser Hinsicht als exzeptionell zu gelten hat ${ }^{4}$ oder auch andere Stücke solche Tendenzen aufweisen, kann an dieser Stelle nicht vorgenommen werden und bleibt weiterführenden Untersuchungen vorbehalten. ${ }^{5}$ )

\section{Vorbemerkungen}

\section{Schaffensprozess und Autorschaft}

Die Aufregung darüber, dass Scelsis Musik seit den 1940er Jahren durchweg auf simprovisierten oder komponierten Tonbändern basiert, die von teilweise hervorragenden `Handwerkern ‘n Partitur übertragen und von Scelsi nur mehr nachträglich überprüft wurden, hat sich mittlerweile gelegt. ${ }^{6}$ Im Falle des vierten Quartetts kann man nach den 2001 in The Musical Times abgedruckten Erinnerungen Franco Sciannameos ${ }^{7}$ davon ausgehen, dass die Ausarbeitung der Partitur im Wesentlichen von Vieri Tosatti übernommen wurde: Er war es, der mit »unfehlbarem Gehör« die Einspielung und Uraufführung

2 Zenck 1983, 70 (zum IV. Quartett), Anderson 1998, 63 f., Koch 1999, 89 f.; Menke 2004 spricht diesbezüglich von Grenzzonen, da der Grenzverlauf sich aus der Sicht jedes Parameters anders darstelle (2004, 36f., 47 ff. u. passim).

3 Siehe vor allem Thein 1993.

4 Auch Scelsi selbst erachtete das Stück für sein CEuvre als zentral und herausragend. So erinnerte sich Franco Sciannameo, seinerzeit zweiter Violinist des Quartetto Nuovo Musica (das 1965 die Ersteinspielung und 1966 die Uraufführung übernahm): „Quartetto No. 4 was, at that time, Scelsi's favorite piece of music, and he was very proud to play our tape for special guests.« $(2001,25)$ - Scelsis hohe Wertschätzung gerade dieses Werks wird ebenfalls durch Harry Halbreich bestätigt, der es überdies als einen Höhepunkt nicht nur in Scelsis Werk, sondern in der gesamten Literatur für Streichquartett einstuft (1989, 20). György Ligeti legte seinen Schülern Mitte 80er Jahre gerade dieses Stück Scelsis ans Herz.

5 Merkwürdigerweise ist die Scelsi-Forschung eine Analyse dieses Werks bislang schuldig geblieben. Martin Zencks Pionier-Beitrag über Scelsis Quartette I bis IV (1983), der das vierte Quartett immerhin ins Zentrum rückt, beschränkt sich neben einigen grundsätzlichen Überlegungen auf die Feststellung, dass die seinerzeit verfügbaren Werkzeuge für eine Analyse dieses Stückes unbrauchbar sind. Unter den Quartetten waren bislang nur das dritte und das fünfte Gegenstand einer eingehenderen Analyse (Thein 1985 und Jäcker 2004.)

6 Zu dieser Frage grundlegend (und auf der Basis zahlreicher Augenzeugenberichte) Jäcker 2004 und 2005; vgl. auch den Bericht Aldo Brizzis in Angermann 1993, 104-106.

7 Sciannameo 2001. 
durch das Quartetto Nuova Musica überwachte, im Zuge der Probenarbeit letzte Änderungen an der Partitur vornahm und diese - so ist zu hoffen - Scelsi zur Prüfung vorlegte. ${ }^{8}$ Am künstlerischen Wert und am `Werkcharakter ändert diese `Koproduktion` nichts.

Die folgende Untersuchung stützt sich auf die von Scelsi autorisierte Partitur und nicht die ihr vorausgegangenen Tonbänder, die - wiewohl digitalisiert und katalogisiert - nach wie vor unerschlossen in der Fondazione Isabella Scelsi ruhen. ${ }^{9}$ Diese haben allenfalls den Status von Skizzen. Als solche sind sie zwar für die Erforschung von Scelsis Arbeitsweise von höchstem Interesse ${ }^{10}$, für die Analyse hingegen - anders als etwa Skizzen zu serieller Musik -verzichtbar. ${ }^{11}$

\section{Notation}

Die Partitur ${ }^{12}$ benutzt für jede saktive`Saite des Quartetts ein eigenes System. So entstehen insgesamt bis zu dreizehn Systeme ${ }^{13}$, die pro Instrument entsprechend den zugehörigen Saiten durchnummeriert sind. Dabei gilt für jedes Instrument eine eigene Scordatur. ${ }^{14}$ Viertelton-Akzidentien sind der besseren Unterscheidbarkeit wegen durch Einkreisungen hervorgehoben. Schlangenlinien bezeichnen ein ıweites` Vibrato; ansonsten gilt vibratoloses Spiel (Abbildung 1, umseitig).

\section{Zu den Prinzipien der Reduktion in Anhang 1}

Im Text wird mehrfach auf die Reduktion in Anhang 1 verwiesen. Dabei handelt es sich um den Versuch, den diastematischen Verlauf der Komposition trotz ihrer komplexen Mikrotonalität grafisch überschaubar zu machen, ohne das Fünfliniensystem preiszugeben. Für ein solches Verfahren spricht neben der leichteren Lesbarkeit auch, dass bei

8 Ebd., 24.

9 Anderson 1999b.

10 Zur eingeschränkten Bedeutung der Tonbänder für die fertige Komposition siehe auch die ernüchternde E-mail Riccardo Filippinis (eines der ,Ghostwriter، Scelsis) an Friedrich Jaecker, sowie dessen Kommentar in Filippini 2005.

11 Zu dieser Einschätzung kommt auf der Basis eingehender Analysen auch Menke 2004, 22 und 242. Gleichwohl bleibt die Forderung nach Freigabe der Tonbänder ein wichtiges Anliegen. Ebenso ohne großen Aufwand realisierbar erscheint mir eine Digitalisierung der hierzulande kaum verfügbaren Einspielung des Quartetto Nuova Musica. Da sie von Scelsi und Tosatti überwacht wurde, sollte sie als aufführungspraktisches Dokument für zukünftige Interpretationen problemlos zugänglich sein.

12 Eine große Hilfe beim Umgang mit dieser klanglich komplexen Partitur war dem Verfasser die exzellente Einspielung durch das Quartett des Klangforums Wien. Der `Nachteil, dass das von Scelsi vorgeschriebene Tempo um fast das Eineinhalbfache unterschritten wird (die Einspielung dauert 14'35 Minuten statt - wie rechnerisch zu erwarten - etwa 10 Minuten), wird durch die Genauigkeit im Detail und durch das musikalische Engagement mehr als aufgewogen. Wer das Stück im Originaltempo hören will, dem sei eine der Einspielungen durch das Arditti-Quartett empfohlen (die Aufnahme von 1983 entstand noch unter Mitwirkung des Komponisten).

13 Vgl. Seite 27 (T. 167-170) der Partitur. Nicht zufällig beginnt diese Seite mit dem ^Höhepunktı des Quartetts. Siehe Anm. 65.

14 Scordatur: 1. Violine: $g-g^{1}-h^{1}-d i s^{2} ; 2$. Violine: $f-d^{1}-d^{2}-f^{2}$; Viola: $d-f-d^{1}-a^{1}$; Violoncello: $C-G-d-c^{1}$. 
(4) = quarter tone higher

(i) = three quarters of a tone higher

(8) = quarter tone lower

(b6) = three quarters of a tone lower

$m$ = wide vibrato (without this indication play non-vibrato)

PONT./TAST. = near the bridge/on the fingerboard

NAT.

LEGNO

= notmal position

= with the back of the bow

FLAUT.

= 'flute' sound

\section{ACCORDATURA}

Violin $1^{\circ} \frac{1}{\%}$

Viola

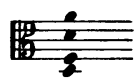

Violino $2^{\circ}$

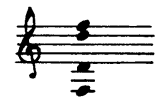

Violoncello

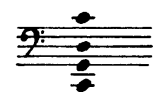

Abb. 1: Scelsi, viertes Streichquartett, Spielanweisungen

Scelsi nicht nur diatonische Intervalle, sondern selbst ıtonale` Akkorde eine zentrale Rolle spielen (was auch mit deren historischem `Gepäckı zu tun hat).

Ebenso klar aber sind die damit verbundenen Probleme: Die Unterscheidung zwischen Einzelton, mikrotonal verbreitertem Stimmen-Strang und Cluster (die im klingenden Resultat ständig ineinander übergehen), zu der diese Notation zwingt, ist immer zu einem gewissen Grade subjektiv, ebenso die Auswahl der je rrepräsentativen Tonhöhe. Die Kriterien wurden von Abschnitt zu Abschnitt neu bestimmt: So werden in Teil A mit seiner noch sehr reduzierten diastematischen Struktur mikrotonale Verbreiterungen nach unten oder oben durch die entsprechenden Gabelsymbole dargestellt. ${ }^{15}$ In den engschrittigen, dabei äußerst nuancierten Abschnitten B 1 und B2 wird von beiden Strängen jeweils der gerade (d.h. nicht getrillerte) Ton gezeigt, in den (auf den Anstieg fokussierten) Abschnitten C1-3 dagegen jeweils der höchste Ton. Die Verteilung auf die drei Systeme erfolgt teils nach Oktavlagen (System 1 zeigt nur die dreigestrichene, System 2 die ein- und zweigestrichene, System die kleine und große Oktave), teils aufgrund satztechnischer Differenzierungen. So wurden in den Abschnitten C1-3 kurzzeitig hinzutretende sowie liegende Satzschichten in System 3 ausgelagert.

15 Mit Ausnahme des Tones c, der eigens notiert wurde, um seine allmähliche Herauslösung abzubilden. 


\section{»Nach oben«:16 Etappen, Durchbrüche und Anfechtungen - erste Aspekte der Formbildung}

The four quartets have one thing in common - a certain ascending line, present in each, even though the language is quite different. ${ }^{17}$

Dass es »nach oben « drängt, hört man dem Stück bereits nach wenigen Takten an. ${ }^{18}$ Diese - für viele Werke Scelsis bestimmende - Tendenz vermag allein aber keine 231 Takte zu stragen`, und sie ist auch keineswegs ununterbrochen wirksam, sondern verläuft in Wellen und wird durch gegenläufige Kräfte gebremst; gerade daraus aber gewinnt der Spannungsverlauf als Ganzes an dramatischer Tiefe.

Konstitutiv für die Form des Stückes sind deshalb vor allem drei Aspekte: seine diastematische Struktur, seine Gliederung in Blöcke ( Wellen $`$ ) aus im weitesten Sinne analogen Teilsegmenten und seine dramatische Struktur.

\section{Diastematische Struktur}

Diastematischer Grundgedanke des Quartetts (vgl. Reduktion in Anhang 1) ist der Anstieg von tief $c^{1}$ (T. 2) bis $b^{1}$ (Vcl., T. 225.3) bzw. - sofern man den Schlussklang dazurechnet - bis $h^{3}$ (VI. 1, T. 227.2). ${ }^{19}$ Er verläuft in mehreren Wellen mit wechselnder >Geschwindigkeit und wird durch herausragende Einzelereignisse und Plateaus gegliedert. ${ }^{20}$ Der Einzelton, der dabei als Ausgangspunkt dient, wird frühzeitig saufgeraut‘, mikrotonal verbreitert und schließlich in zwei Stränge zerteilt (T. 34), deren Abstand im weiteren Verlauf bis zur Quarte wächst; nur der höhere, beweglichere Strang legt den vollständigen Anstieg zurück. Sporadisch und kurzfristig hinzutretende Einzeltöne ergänzen die beiden Stränge zu akkordähnlichen Gebilden; andernorts werden sie clusterähnlich verbreitert und zusammengeführt.

16 Vgl. Anm. 18.

17 So Scelsi im Jahre 1983, d. h. 19 Jahre nach Abschluss des vierten Quartetts, im Plattentext zur (ersten) Einspielung der Quartette I-IV durch das Arditti-Quartett (1983, 1).

18 Gegenüber Irvine Arditti wurde Scelsi noch expliziter: Er beschrieb die vier ersten Quartette »als einen Aufstieg (zum Himmel) « (Jaecker 2004, 70). Unter das Motto »Nach oben« (als psychologische Konstante) stellte die Pianistin Marianne Schroeder ihren Nachruf: »Alles musste nach oben gehen. Kein Kleben an der Erde. Nicht perfekt sein wollen, sondern perfekt sein müssen, um weitergehen zu können. Erst bei der Perfektion fange der Weg an.« (Schroeder 1988, 27)

19 Vgl. Zenck 1983, 72 f.; Markus Bandur spricht angesichts von Werken wie dem 4. Streichquartett und Anahit von "einer Art Makroglissando« $(2007,11)$. - Mit den Bezeichnungen hoch $c^{1}$ bzw. tief $C^{1}$ wird im Folgenden auf die Tonhöhen referiert, die sich laut Partitur einen Viertelton über bzw. unter $c^{1}$ befinden.

20 Anderson deutet den ebenfalls ansteigenden Grundriss in Anahit (1965) im Sinne einer Bedeutungskomponente des Titels, die in der Yoga-Praxis als der »richtige« Klang bekannt ist: »Diese Gehörserscheinung (auf Hindi anâhid, Scelsi: anahad) wird als stetig ansteigender Ton beschrieben.« (1998, 66). 


\section{Form-Blöcke und Zyklizität}

Mit den üblichen Einschränkungen, die für die Analyse prozesshafter und kontinuierlicher Formen gelten ${ }^{21}$, lässt sich das Quartett in drei Teile gliedern, die sich anhand auskomponierter Zäsuren, spezifischer, innerhalb der jeweiligen Formteile wiederkehrender Form-Komponenten bzw. Folgen von Form-Komponenten sowie deren `Geschwindigkeit und Intensität voneinander abgrenzen lassen (vgl. Tabelle 1). Alle drei Teile sind auf ihre Weise - und in zunehmendem Maße - zyklisch konzipiert.

Demnach erfolgte in Teil A der erste, vierteltönig abgestufte Anstieg von tief $\mathrm{C}^{1 / 2}$ bis $d^{1 / 2}$, die Teilung des Tons` in zwei Stränge und eine erste Öffnung des Tonraums von der ein- und zweigestrichenen in die dreigestrichene und kleine Oktave, gegen Ende für einen Moment sogar in die viergestrichene Oktave. Die Zyklizität ist in diesem Teil am schwächsten ausgeprägt: Der vierteltönige Stufengang wird, da er mit einem Prozess der Verbreiterung (vom Ton zum Klang) einhergeht, durch eine von Tonstufe von Tonstufe wechselnde Auswahl an Komponenten realisiert.

Teil B, im engsten Umkreis seines Ausgangstons $d$ erharrend, exponiert mit der Unterscheidung zwischen oszillierendem und liegendem Strang, mit Übergängen zwischen Harmonizität und Inharmonizität und ersten, vorsichtigen Dreiklangsbildungen die für die folgende Steigerung bestimmenden satztechnischen und formalen Komponenten, darunter auch die Oszillation als ein wesentliches treibendes Moment. In all dem erweist sich B2 als die steigernde und um zusätzliche Komponenten angereicherte Variante von B1.

Teil C, der dramatische Kernbereich des Quartetts, zerfällt in drei über weite Strecken analoge Anläufe zum diastematischen Höhepunkt, von denen der erste bogenförmig, der zweite plateau-artig verharrend und der dritte kontinuierlich ansteigend ist. Die Zyklizität umfasst hier die Wiederholung ganzer Stimmenauszüge in neuer Transposition und neuer satztechnischer Umgebung.

\begin{tabular}{|c|c|c|c|c|}
\hline Formteil & Abschnitt & Takte & $\begin{array}{l}\text { Zentral- bzw. } \\
\text { Liegeton }\end{array}$ & $\begin{array}{l}\text { (Ausgangston und) Hochton des } \\
\text { oszillierenden Strangs }\end{array}$ \\
\hline A & & $1-46$ & tief $c^{1 / 2}$ bis $d^{1 / 2}$ & - \\
\hline \multirow[t]{2}{*}{ B } & $\mathrm{B}_{1}$ & $47-74$ & hoch $\mathrm{Cis}^{2} / \mathrm{Cis}^{2}$ & $\left(d^{2}\right)-e^{2}\left[\right.$ tief $\left.f^{2}\right]$ \\
\hline & $\mathrm{B}_{2}$ & $74-112$ & $\mathrm{C}^{2} / \mathrm{Cis}^{2}$ & $\left(\right.$ hoch $\left.d^{2} / d i s^{2}\right) e^{2}\left[f^{2}\right]$ \\
\hline \multirow[t]{3}{*}{ C } & $\mathrm{C}_{1}$ & $113-157$ & $\operatorname{cis}^{2}(113) / e s^{2}(140)$ & $\left(e^{2}\right) a^{3}(139)$ \\
\hline & $\mathrm{C}_{2}$ & 158-195 & $d^{1}$ & $\left(f^{2}\right) a s^{3}(174)$ \\
\hline & $\mathrm{C}_{3}$ & $196-231$ & $d^{1 / 2}-e s^{2}-e^{3}$ & $\left(f^{2}\right) b^{1 /}$ hoch $a^{3}(226) ;\left[h^{3}(227)\right]$ \\
\hline
\end{tabular}

Tabelle 1: Scelsi, viertes Streichquartett, Formteile

21 Hierzu grundsätzlich Menke 2004, 36 f. 


\section{Dramatische Struktur}

It seems that with different languages every quartet tells the same story and that after returns, contrasts and dramas the finale is always a liberation, a catharsis. ${ }^{22}$

All diese vorwiegend diastematischen Aspekte bleiben jedoch einer übergreifenden dramatischen Konzeption unterworfen, nämlich Genese, Anstieg, Auf- und Verblühen, schließlich `Abheben und intern bewegten Ganzen, mit den Ingredienzien des Zögerns, des Drängens, der Ekstase, des Leidens, des (`inneren $`$ Ringens, der Befreiung und Katharsis. ${ }^{23}$ Hinweise zu einer solchen - für ihn überraschend traditionellen und seuropäischen « - Deutung ${ }^{24}$ hat Scelsi selbst geliefert (wenngleich aus dem Abstand von beinahe zwei Jahrzehnten), erstens mit dem oben zitierten Kurzkommentar, zweitens indem er - diese generelle Anmerkung exemplifizierend - zum dritten Quartett folgende Satzüberschriften mitteilte: ${ }^{25}$

I. avec une grande tendresse (dolcissimo)

II. I'appel de l'esprit: dualisme, ambivalence, conflit (drammatico)

III. I'âme se réveille (con transparenza)

IV. [...] et tombe de nouveau dans le pathos mais maintenant avec un pressentiment de la libération (con tristezza)

V. libération, catharsis.

Abgesehen von der neutralen Überschrift des ersten Satzes ist die Ähnlichkeit mit der herkömmlichen Bezeichnung der fünf Teile des sklassischen`Dramas kaum zu übersehen $^{26}$ - freilich mit dem Unterschied, dass, wie offenbar auch in den Quartetten I, II

\section{Scelsi 1983, 1.}

23 Der Begriff >Dramaturgie، begegnet in der Scelsi-Literatur des öfteren. So beginnt Anderson ihre Analyse von Anahit mit einer "Dramaturgie der Abschnitte« (1998, 67-70). Dabei geht es jedoch weniger um Fragen der kompositorischen Gestaltung als um eine Beschreibung des Höreindrucks. Menke analysiert unter diesem Begriff teils die einen Satz überwölbende sSpannungskurve` (vgl. z. B. Menke 2004, 40 f.), teils aber auch Fragen der Gestaltung und der Interpretation (ebd., 50-54). Theins Analyse des dritten Quartetts (1985) löst das Versprechen des (nachträglichen?) Publikationstitels (»Drama und Katharsis«) nicht ein.

24 Dramenorientierte Konzeptionen bestimmen die Instrumentalmusik spätestens seit der Wiener Klassik, und nicht erst seit Antonin Reicha werden sie auch in diesem Sinne interpretiert bzw. analysiert. Im 19. Jahrhundert scheint es, als erfolge in der Komposition nicht nur die Anwendung derartiger Konzeptionen auf traditionelle Formmodelle, sondern, als brächten diese selbst neuartige musikalische Formen hervor (z. B. in der Symphonischen Dichtung). Für die Analyse bedeutet diese Entwicklung wiederum, dass die Diskrepanz zwischen Form- und Analysemodell, wie sich beispielsweise noch in der Sonatentheorie Reichas bei der Deutung der Reprise zeigt, zunehmend gegenstandslos wird. Umso mehr erstaunt es, dass dramenorientierte Deutungsmodelle in der Analyse von Instrumentalmusik des 20. Jahrhunderts eine so geringe Rolle spielen.

25 Die Überschriften gehen auf Informationen Halbreichs im Begleittext zur Einspielung des ArdittiQuartetts für Salabert zurück (Halbreich 1989, 18 und Thein 1993, 63).

26 Von den verschiedenen Darstellungen des fünfteiligen Dramas (umstritten ist vor allem die Verteilung der aristotelischen `Episoden ‘ auf die Teile bzw. Akte II-IV) am nächsten kommt die von Gustav Freytag mit »a) Einleitung, b) Steigerung, c) Höhepunkt, d) Fall oder Umkehr, e) Katastrophe« (2003, 95). 
und IV, die «Katharsis`, die im klassischen Drama weniger in den handelnden Personen als im Zuschauer vonstatten gehen soll - selbst zum Teil der `Handlung، wird. Aufschlussreich ist zudem - gerade auch im Hinblick auf das vierte Quartett -, dass das `Erwachen der Seele` und die `Befreiung` mit einem Ausweichen ins hohe Register, der 'Rückfall ins Pathos` aber mit tonalen Akkordbildungen im Mittelregister verknüpft ist. ${ }^{27}$ Letztere markieren nicht nur als Akkorde (reine Durdreiklänge), sondern ganz explizit als (nicht mehr ganz frische) spätromantische Mediantverbindung (B-Dur und Ges-Dur) tatsächlich einen >Rückfallı, nämlich in ein kompositionsgeschichtliches Stadium, das zwar nostalgische Erinnerungen wecken mag, aber auf diese Weise nicht mehr wiederzubeleben ist. ${ }^{28}$ Wie zu zeigen sein wird, begegnen analoge Dreiklangsbildungen und Großterzbeziehungen, wenngleich auf subtilere Weise, auch im vierten Quartett an für den dramatischen Verlauf entscheidender Stelle.

Keiner der genannten Aspekte ist für sich genommen tragfähig (und analytisch hinreichend): Der Anstieg ist als solcher nur nachvollziehbar, wenn er mit Ausblicken (auf den Gipfel und rückwärts), Irrwegen und gefahrvollen Situationen (`dramas`) verknüpft ist; Zyklizität trägt nur, wenn sich zwischen den analogen Formblöcken eine wie auch immer gerichtete Veränderung abzeichnet; und ein musikalisches Drama bedarf musikalischer Strukturen, Konflikte und dramatis personae, um sich zu entfalten. Eine säuberliche Trennung zwischen den drei Formteilen wird es deshalb auch in den folgenden Analysekapiteln nicht geben können. Vielmehr stellt jedes der drei Kapitel bestimmte analytische Aspekte in den Vordergrund: In I sind dies die satztechnischen und syntaktischen Voraussetzungen, in II die Gestaltung eines wichtigen Übergangs und in III das Prinzip variabler Zyklen und der Zusammenhang zwischen Zyklizität und Dramenkonzept. Zudem dient die Analyse jeweils eines Teilabschnittes als Bezugspunkt einer eher summarischen Analyse des restlichen Formteils. In Kapitel IV wird auf dieser Grundlage eine sdramatische` Deutung des gesamten Quartetts versucht.

\section{Exposition (Formteil A, T. 1-46)}

\section{'Stufengang,}

Bereits der erste Teil (vgl. Tabelle 2 und Reduktion in Anhang 1) exponiert den Anstieg als Grundfigur und die Tiefendimension des Tons bzw. dessen Ambivalenz zwischen Ton und Klang ${ }^{29}$ als `Gegenstand des Quartetts. Ausgangspunkt ist der Einzelton (zunächst tief $C^{1}$ ). Dieser wird in Schwingung versetzt, angehoben, mikrotonal verbreitert, in zwei Stränge geteilt, die später auch lagenmäßig (durch Oktavierung) getrennt und durch einzelne Töne im Unterquartabstand gestützt werden und schließlich vorübergehend und zäsursetzend - im Unisono zusammenfinden.

27 Vgl. Thein 1992, 63.

28 Der >Rückfalk bezieht sich zugleich auf den ersten Satz, mit dem der vierte in leicht variiertem Krebsgang verbunden ist, vgl. Thein 1992, 63, sowie Thein 1985, $36 \mathrm{f}$.

29 Vgl. Zenck 1983, 68. 
Der Anstieg erfolgt in Vierteltonschritten, wird jedoch durch kleine Unregelmäßigkeiten verschleiert und scheint überdies nach der Teilung der Stränge zurückgestuft, indem der obere Strang um einen Halbton zurückliegt. Die Erweiterung des Ambitus der letzten Stufe $(\curvearrowright D \prec)$ durch eine nochmalige Oktavierung von zuletzt drei auf fünf Oktaven bereitet die Entwicklung in den Formteilen B und C vor (zwei Stränge), bzw. nimmt diese in einzelnen Aspekten (Anstieg, Entfaltung des Tonraums, Unterquarte als Stützintervall, der Ton $d$ als Zielton) bereits vorweg.

\begin{tabular}{|c|c|c|c|c|c|c|c|}
\hline Stufe & Zentralton & Setzung & $\begin{array}{l}\text { Störung } \\
\text { oben }\end{array}$ & $\begin{array}{l}\text { Störung } \\
\text { unten }\end{array}$ & Ruhe (Unis.) & $\begin{array}{l}\text { Störung } \\
\text { II }\end{array}$ & pizz.-Akzent \\
\hline 1 & tief $c^{1 / 2}$ & T. 2 & T. 6 & T. 10 & T. $3-6$, T. 11 & T. 14 & T. $7\left(\right.$ tief $\left.\operatorname{ces}^{1}\right)$ \\
\hline II & $c^{1 / 2}$ & T. 17.3 & T. 19 & T. 20 & T. 20.3 & T. 22 & T. $19\left(c^{1}\right)$ \\
\hline \multicolumn{8}{|c|}{ Verbreiterung und Abspaltung von Stufe ${ }^{\prime} C_{C}$} \\
\hline III & hoch $\mathrm{c}^{1 / 2}$ & T. 23.2 & T. 23.2 & T. 23.2 & & & $\begin{array}{l}\text { T. } 24.3\left(c^{1}\right), \text { T. } 26.3 \\
\left(\text { tief des }{ }^{1}\right)\end{array}$ \\
\hline IV & $d e s^{1 / 2}$ & T. 28 & T. 28 & T. 28 & & & $\begin{array}{l}\text { T. } 30\left(c^{2}, \text { ohne }\right. \\
\text { pizz.), T. } 31, \text { T. } 34 \\
\left.\text { (jeweils } c^{1}\right)\end{array}$ \\
\hline \multicolumn{8}{|c|}{ Abstützung durch Unterquarte } \\
\hline V & $c^{3} / d e s^{2}$ & T. 34 & & & & & T. $35\left(c^{1}\right)$ \\
\hline VI & $\begin{array}{l}\text { tief } d_{\text {es }}^{3}, \\
\text { tief } d^{2}\end{array}$ & T. 36.3 & & & & & $\begin{array}{l}\text { T. } 36.3 \text { und T. } 38.2 \\
\left(\text { tief } d^{1}\right)\end{array}$ \\
\hline \multicolumn{8}{|c|}{ Unisono, pp } \\
\hline VII & tief $d^{3} / d^{1}$ & T. 40 & & & T. 40 & & \\
\hline VIII & $\begin{array}{l}d^{3 / 2}(\text { T. 42) } \\
d^{1 / d}(\text { T. 43) }\end{array}$ & T. 42 & & & T. 42 & & \\
\hline
\end{tabular}

Tabelle 2: Scelsi, viertes Streichquartett, 'Stufengang` im ersten Formteil

Wesentlich für die diastematische Entwicklung sind drei Komponenten, die vor allem den vierteltönigen Stufengang des Zentraltons zum Gegenstand haben: Formen der `Setzung، - in Gestalt eines Unisono (T. 2.3: tief $c$, T. 17.3: c), einer clusterartigen Verbreiterung (T. 23.3: tief des, T. 28: des) oder eines Akzents (T. 34: c) ${ }^{30}$-, der (meist vorübergehenden) `Auslenkung`(nach oben) im je tieferen Register (T. 18.3 f.), sowie der >Ausholung، (von unten) ${ }^{31}$ in beiden Registern, die entweder eine bereits eingetretene Stufe bestätigt (T. 10, 20.2 f.) oder eine neue einführt (T. 23).

Hinzu kommen zwei Komponenten, die einem einzelnen Ton mehr Nachdruck verleihen: Ein sPochen (Portato in Achteln bzw. Triolen-Achteln) in Phasen der relativen Ruhe (T. 11, 17.3 f., 32.3 f., vgl. aber den Störton in T. 13.3) und pizzicato-gestützte sEin-

30 Hier nimmt der 'Stufengang` des >oberen Strangs` seinen Ausgang.

31 sNach oben 
zelakzente in Momenten der lebhaften Oberflächenbewegung (T. 7.2, 19.3, 24.3, 26.3, 31.2). Meist ist es der Ton $c$, der auf diese Weise eine Vorrangstellung behauptet.

Schließlich sind unterschiedliche Abstufungen von `Vibration « - Bariolage, vibrato ampio und Tremolo - gleichsam passiv am diastematischen Geschehen beteiligt, indem sie auf bestimmte Veränderungen reagieren, sie vorfühlen oder begleiten.

\section{Zyklizität}

Der musikalische Verlauf hat eine leichte szyklische` Tendenz, insofern einige Komponenten mehrfach wiederkehren, und zwar häufig an (in Bezug auf den Stufengang) analoger Stelle. Die wenigsten dieser Gesten werden in identischer Form wiederholt. Eben daran aber - an ihrer Veränderung, ihrem Verschwinden oder ihrer Störung durch nichtzyklische Komponenten - ist der Verlauf als vielschichtiges und dramatisches Geschehen erfahrbar.

Je zwei Stufen dieses Prozesses werden auf einander ähnliche Weise gestaltet: Während I und II die allmähliche `Belebung` des Einzeltons (Pulsation und Schwebung), das In-Gang-Setzen einer ansteigenden Bewegung und die Widerstände, die ihr entgegenstehen, zum Gegenstand haben, geht es in III und IV um die (spannungsvolle) Verbreiterung des Tons und seine sSpaltung in zwei Stränge. Und während auf den Stufen V und VI mit der Abstützung durch die Unterquarte ein erstes sakkordisches` Element ins Spiel gebracht wird, wird auf den Stufen VII und VIII mit dem `Abzug der Unterquarte, einer dynamischen und bewegungsmäßigen Zurücknahme, der Annäherung der Stränge bis zum Oktavklang und einer schlagartigen Öffnung des Tonraums die erste große Zäsur vorbereitet. Aus dieser formfunktional unterschiedlichen Gestaltung der Stufen resultieren je unterschiedliche Verlaufsmodelle.

Zunächst seien - als >Modell für den gesamten Stufengang - die Takte 1-18 etwas ausführlicher analysiert:

Initiale und Stufe I (T. 1-3 und T. 4-18)

Nicht der Einzelton (oder seine sukzessive Entfaltung ${ }^{32}$ ), auch nicht der Anstieg als Grundfigur des Quartetts ist es, was sich dem Hörer als Erstes darbietet, sondern eine vierfache Verwandlung: die Überlagerung und Verdrängung eines Ausgangstons durch seinen unteren vierteltönigen Nachbarton, die Verdrängung einer eher hellen, obertonreichen Farbgebung (sul ponticello) durch eine eher >dunkle` (sul tasto) - wobei mit dem tief $c^{2}$ der Viola zugleich die obertönige Komponente des Ausgangsklangs sausinstrumentiert ` wird -, die Auslösung, Weitergabe und erste Abbremsung eines Schwingungsimpulses (als Schwebung ${ }^{33}$, Bariolage und auskomponiertes Ritardando von Triolenvierteln auf punktierte Viertel), und schließlich - aus dem Vorigen resultierend - die sukzessive Verbreiterung des Einzeltons zum komplexen »Ton als Klang«. ${ }^{34}$

32 Die sukzessive Entfaltung eines Einzeltones findet sich etwa bei Ligeti im Konzert für Violoncello und Orchester (1966) und im Streichquartett Nr. 2,ii (1968).

33 Rechnerisch entsteht zwischen $c^{1}$ und tief $c^{1}$ (bei Kammerton auf $440 \mathrm{~Hz}$ ) eine Schwebungsfrequenz von $8 \mathrm{~Hz}$, was bei Viertel = 69 einer Sechzehntel-Septole entspräche. 
Damit sind mit äußerst sparsamen Mitteln der Gegenstand des Quartetts und die es bestimmenden Verfahrensweisen exponiert: der `Ton als Klang`, d. h. als im mikrotonalen Rahmen bewegliches, in sich mehrschichtiges und aus wechselnden Komponenten zusammengesetztes, vibrierendes Ganzes, sowie dessen allmähliche Veränderung durch Überlagerungen und Verlagerungen zwischen Klangfarben und Oktavlagen derselben Tonqualität, zwischen vierteltönig benachbarten Tonhöhen und durch vielfache Formen der inneren Pulsation (hier Schwebung und Bariolage).

Zugleich hat diese Eröffnung etwas Irritierendes: Noch ehe ihm Gelegenheit gegeben wird, sich zu entfalten, wird der Ton bereits abgesenkt; das temporale >Missverhältnis zwischen dem einleitenden c (T. 1) und dem als Zentralton bis Takt 18 gültigen tief $c$ (ab T. 2) suggeriert, unvermittelt in einen Prozess einzutreten, der schon längst begonnen hat.

In den Takten 4 und 5 wird in raschen Schritten das Klangspektrum sowohl in Richtung der Grundfrequenz (Wechsel der 2. VI. zur normalen Bogenposition; Einsatz der 4. Saite der Vla.), als auch (zunächst) in Richtung der hohen Partialtöne (sul ponticello auf tief $c^{2}$ ) erweitert; ein erstes Frequenz-Vibrato setzt ein (2. VI.), die Pulsation erfolgt in Achteln, Crescendi verleihen dem Klang zusätzliche Fülle. Dieses >Aufblühen ist mit Beginn der zweiten Schwebung (T. 6) schlagartig zu Ende: Mit Ausnahme eines leichten Crescendo auf dem Schwebungston $c^{1}$ und eines vorsichtigen Gegenakzents (pizzicato) auf dem Zentralton tief $c^{1}$ bleibt der Klang nun für die Dauer von $7 / 4$ unverändert und nahezu ohne Pulsation. Erst mit der Auflösung von $c^{1}$ und mit der sich anschließenden, rausgleichenden Auslenkung nach unten setzt eine erneute, wiederum beschleunigte Pulsation ein. Der zweite Teil dieser Ausgleichsbewegung wird von der 2. Violine als ,Vorhalt heterophon überzeichnet. Mit dessen Auflösung tritt abermals eine Phase der Ruhe, der Zurücknahme und der Verengung ${ }^{35}$ ein (T. 10.3); anders als beim Schwebungsklang hält hier ein gleichmäßiges Pochen der 2. Violine eine Bewegung aufrecht, an die im Folgenden (T. 12 f.) angeknüpft werden kann.

Ein erneutes `Aufblühen - eine Verbreiterung des Klangspektrums, die die Grundfrequenzen stärker hervortreten lässt ${ }^{36}$ und ein Wiedereinsetzen der sweichen ` Vibrationen (Vibrato, in Verbindung mit Bariolage in Triolen und Quintolen) - wird durch den dritten Schwebungsklang (ab T. 13.3) wiederum schlagartig beendet. Die bereits aus den Takten 2.2 und 6.3 bekannte Konstellation $c^{1}$ vs. tief $c^{1 / 2}$, in der $c^{1}$ als Störton gegenüber dem oktavierten Zentralton akustisch zurücktritt, wird durch das sausholende der 1. Violine zu einem aus fünf Tönen und drei Tonqualitäten bestehenden Schwebungsklang verbreitert, der den Zentralton nun auch in der zweigestrichenen Oktave übersteigt und durch ein tremolo con legno an Dramatik gewinnt. Bei dessen Auflösung entsteht zudem eine akustische Täuschung: Indem $c^{1}$ als `Störton` mit den gleichen

34 Der Begriff »Ton als Klang« wurde von Martin Zenck geprägt $(1983,71)$. Der weniger sperrige Begriff des »komplexen Tons" (Murail) ist durch die Theorie der musique spectrale (als "son complex«) zu sehr mit einer bestimmten Stilrichtung verknüpft, als dass man ihn auf Scelsi anwenden könnte, ohne Missverständnisse auszulösen.

35 Sul tasto der 2. Violine, Ausblendung der 4. Saite der Viola, Reduzierung auf drei (statt zuletzt fünf) Saiten, flautando der 1. Violine und Verzicht auf 'weiche` Formen der Vibration.

36 Wechsel zur normalen Bogenposition und zur 4. Saite der Viola, dynamische Verstärkung von tief $C^{1}$. 
pochenden Achteln eingeführt wird, mit denen es schließlich als neuer Zentralton aus der Schwebung heraustritt, entsteht der Eindruck, Ausgangs- und Zielpunkt dieser Verlagerung seien gleich. Wie schon beim merkwürdigen Beginn dient auch diese Maßnahme dazu, dem vierteltönigen Anstieg etwas von seiner Voraushörbarkeit zu nehmen.

Damit sind weitere Eigenschaften des Tons bzw. Klangs exponiert, die seine Wahrnehmung als shandelnde Person verstärken: Da ist zunächst das Alternieren zwischen der Schwingung des Tons, die - als Schwebung, Vibrato oder Pulsation - den Normalzustand darstellt, und ‘äußeren` (diastematischen) Veränderungen, die als `Störungen` dieses schwingende Gleichgewicht beeinflussen bzw. aus der Ruhe bringen. Darüberhinaus suggeriert die Intensität, mit der neue Töne ins Spiel gebracht werden oder der Zentralton wieder in Erinnerung gerufen wird, dass es sich um ein dramatisches Geschehen handelt (dessen Konflikte freilich eher sinnerer Art sind).

Stufe II (T. 17-22)

Die Ausgestaltung der Tonhöhenstruktur auf Stufe II folgt weitgehend der auf Stufe I: Der neue Zentralton $c$ wird zunächst je einmal durch seinen oberen und unteren vierteltönigen Nachbarn sgestört ‘ (wiederum ohne $c^{2}$ als Grenzton in Frage zu stellen - T. 19 und 20.2, Vcl., vgl. T. 6 ff. und 10), setzt einen Gegenakzent (T. 19.3 und 20.2, Vl. 2, vgl. T. 7), wird dann durch ein pointiertes tief des ${ }^{1}$ aus der eingestrichenen Oktave verdrängt (T. 21.3-22.2, vgl. T. 1337), ehe 1. Violine und Viola. mit einem fast ıübertriebenen Glissando von hoch $h$ zur sendgültigen Verlagerung ausholen, die auch die zweigestrichene Oktave erfasst $^{38}$ (T. 23.1, vgl. T. 14). Auffallend auch hier der enge Zusammenhang zwischen diastematischer Veränderung und Pulsation: Nach einer zunächst zurückhaltenden und eher pochenden als fließenden Pulsation (T. 17.3-19.2, VI. 2 und Vla.) stoßen die beiden Akzente in den Takten 19.3 und 20.2 - die ihrerseits auf Störungen reagieren - je eine Schicht einer gleichmäßigen Sextolenpulsation an. Diese wird durch den zweiten, massiveren Einsatz von tief des ${ }^{1}$ unterbrochen (T. 22.2) und erst nach der sendgültigen Verlagerung in Takt 23.2 wiederaufgenommen. ${ }^{39}$ Auch hier ist es ein ausgeprägtes Portamento (Vl. 1, Vla. Vcl.), das die nächste Stufe einleitet.

Stufen III (tief des, T. 23-27) und IV (des, T. 28-33)

Mit den Stufen III und IV (T. 23-27 und 28-33) verzweigt sich der Klang bis hin zu einer Trennung in benachbarte Register. Ausgangspunkt ist beide Male - und in Umkehrung der bisherigen Klangverhältnisse - ein clusterartig verbreiterter Klang, der im Folgenden ausgefiltert wird (vgl. Tabelle 3).

Der je neue Substanzton (tief des bzw. des) fungiert zwar in der zweigestrichenen Oktave als oberer Grenzton, ist aber in der eingestrichenen Oktave von seinen unmit-

37 Takt 14 ist ohne diese Verdrängung.

38 Das Erscheinen von tief des in der zweigestrichenen Oktave - d. h. als höchster Ton - verleiht dieser Tonqualität offenbar noch einmal deutlich mehr Gewicht als ihre starke Präsenz in der eingestrichenen Oktave im Takt zuvor; sie rückt ins Zentrum des Tonstrangs.

39 Weitgehend synchron dazu ist auch das Ein- und Aussetzen des Vierteltonvibratos. 


\begin{tabular}{|c|c|c|c|c|c|c|c|c|c|c|c|c|}
\hline Stufe & III & & & & & IV & & & & & & \\
\hline \multirow[t]{9}{*}{ Takt } & 24 & 25 & 26.1 & 26.3 & 27.2 & 28 & 29.3 & 30.3 & 31.1 & 31.3 & 32.1 & 33.1 \\
\hline & & & & & & $d e s^{2}$ & $d e s^{2}$ & & $d e s^{2}$ & $\operatorname{des}^{2}$ & $d e s^{2}$ & $d e s^{2}$ \\
\hline & $d e{ }^{2 *}$ & des- $^{2}$ & & des $-^{2}$ & $d e s{ }^{2}$ & & & & & & & \\
\hline & $C^{2}$ & $C^{2}$ & $C^{2}$ & $C^{2}$ & & $C^{2}$ & $c^{2}$ & $C^{2}$ & $C^{2}$ & $c^{2}$ & $C^{2}$ & $C^{2}$ \\
\hline & & & & & & $C-{ }^{2}$ & & $C-{ }^{2}$ & $C-{ }^{2}$ & $C-{ }^{2}$ & & \\
\hline & & & & & & $d-1$ & $d-1$ & $d-^{-1}$ & $d-1$ & $d-^{1}$ & $d-^{-1}$ & $d-1$ \\
\hline & $d e s^{1}$ & & & $d e s^{1}$ & $d e s^{1}$ & $d e s^{1}$ & & & $d_{e s}^{1}$ & $d e s^{1}$ & des $s^{1}$ & \\
\hline & des- $^{-1}$ & des- ${ }^{1}$ & des- ${ }^{1}$ & des $^{-1}$ & des $-^{1}$ & & & & & & & \\
\hline & $C^{1}$ & $c^{1}$ & $c^{1}$ & & & & & & & $C^{1}$ & $C^{1}$ & $C^{1}$ \\
\hline Töne** & 5 & 4 & 3 & 4 & 3 & 5 & 3 & 3 & 5 & 6 & 5 & 4 \\
\hline Tonqu.*** & 3 & 2 & 2 & 3 & 2 & 4 & 3 & 3 & 3 & 4 & 4 & 3 \\
\hline
\end{tabular}

Tabelle 3: Scelsi, viertes Streichquartett, clusterartige Verbreiterung und Ausfilterung auf der III. und IV. Stufe; ${ }^{*} d-^{1}$ : tief $d^{1}$; ** Anzahl der unterschiedlichen Töne; ${ }^{* * *}$ Anzahl der unterschiedlichen Tonqualitäten

telbaren mikrotonalen Nachbarn derart sumhüllt ${ }^{40}$, dass seine Vorrangstellung fraglich ist. Ansonsten sind die Komponenten im Wesentlichen dieselben wie auf der zweiten Stufe: eine gleichmäßige Sextolenpulsation ${ }^{41}$, ein oberer vierteltöniger Nachbarton im eingestrichenen Register (des ${ }^{1}, V_{c l}$., T. 23), der sich zu Takt 25 hin auflöst ${ }^{42}$ und pizzicato-gestützte Akzente (T. 24.3 und 26.3). ${ }^{43}$ Doch schon die Tatsache, dass der erste der beiden Akzente das soeben überschrittene $c^{1}$ reaktiviert und erst der zweite den neuen Substanzton tief des stützt, weist auf einen Konflikt hin. Der Akzent in Takt 24.3 ist der erste in einer Reihe von Aktionen, mit denen sich der Ton $c$ als übergeordneter Zentralton zu sbehaupten` sucht. Bereits aus dem hier folgenden Ausschwingvorgang tritt c gestärkt hervor - als oberer Grenzton und einziger oktavgestützter Ton (T. 26.1-2).

Der Übergang zu Stufe IV folgt dem Modell der beiden vorigen Übergänge: Aufgreifen der spannungsvollen Konstellation vom Beginn der Stufe III (T. 26.3-27.3, vgl. T. 23.2: tief $\left.d e s^{1 / 2}-c^{2}-d e s^{1}\right)^{44}$, Innehalten, partielle Auflösung (T. 27.2 $)^{45}$ und weitge-

40 Auch hier signalisiert das Erscheinen des oberen Nachbartons im zweigestrichenen Register, und damit die Überschreitung des Substanztons als Grenztons, die sendgültige ‘ Verlagerung: des ${ }^{2}$ in Takt 28, hoch des ${ }^{2}$ in Takt 37.

41 Vgl. Takte $20 \mathrm{f}$.

42 Vgl. 1. Violine, Takte $19 \mathrm{f}$.

43 Vgl. Takte 19.3 und 20.2.

44 Auf den Stufen I und II ist es selbstverständlich nicht das Unisono, sondern der jeweils erste Schwebungsklang, vgl. Takt 22.1 bzw. Takt 19 und Takt 13.3 bzw. Takt 6.3.

45 Das $c^{2}$ der 1. Violine löst sich mit Takt 27.2 geichsam in das tief des $^{2}$ der 2. Violine auf; ähnlich führt in Takt 22 ein Glissando des Violoncello aus einem dreitönigen in einen zweitönigen Klang. 
hender Verzicht auf Pulsationen ${ }^{46}$, Portamento nahezu aller Stimmen in Richtung des neuen Substanztons (27.3-28.1) ${ }^{47}$ Ergebnis ist der (mit vier Tonqualitäten und fünf Tönen) bislang komplexeste Klang (T. 28.1), der sich auch spieltechnisch und dynamisch als Krisenklang präsentiert. ${ }^{48}$ Mit ihm - und mit der Ausblendung des vorigen Substanztons tief des (bis Takt 36.3) - ist eine Auftrennung des Klangs in zwei halbtönig entfernte Stränge vorbereitet. Der Ton c, der damit von vornherein sabgehoben ist, tritt in den Takten $30 \mathrm{ff}$. immer plastischer und schärfer hervor ${ }^{49}$, so dass er mit Takt 34 ins nächsthöhere Register projiziert werden kann.

Stufen V-VIII: Anstieg, Register-Öffnung und erste dreitönige Zusammenklänge

Damit ist die Trennung der Stränge vollzogen: Durch die Oktavierung erscheint $c^{3}$ als quasi leittönige große Septime über dem Strang der übrigen Stimmen und wird als solche nach Art einer umgekehrten Syncopatio nach oben getrieben (tief des ${ }^{3}$ : T. 36, tief $d^{3}$ : T. 40, d: T. 42); der `Vorsprung ‘ der Unterstimmen verringert sich sukzessive, so dass die beiden letzten Stufen des Anstiegs bereits im Unisono erklingen. Das Erreichen von $d$ wird durch eine beidseitige Erweiterung um je ein Oktavregister als emphatische `Öffnung inszeniert. In dem Maße, wie sich der Anstieg beschleunigt und ästhetisch in den Vordergrund rückt, verringert sich die mittlerweile erreichte (mikrotonale) Komplexität der Klänge: Der Gerüstklang in Takt 37 (Stufe VI) ist bereits diatonisch (entsprechend tief a, tief $d$ und tief cis), die Stufen tief $d$ und $d$ (VII und VIII) erklingen mehr oder weniger ausgiebig im Unisono. ${ }^{50}$

Anfang und Ende dieses Anstiegs werden überdies von Tönen im kleinen Register begleitet, die in Gegenbewegung an die Töne des drei- und viergestrichenen Registers gekoppelt sind (T. $36 \mathrm{ff}$. und $44 \mathrm{f}$. tief a und $g$ bzw. tief as). Ohne dass man sie bereits zwingend als tonal wahrnehmen müsste ${ }^{51}$, sind diese ersten `dreistimmigen Z Zusammenklänge (die auch dynamisch hervortreten) bereits Vorschein späterer Dreiklangsbildungen (T. 117: A-Dur, T. 164: B-Dur).

46 Ähnlich wie im analogen Klang auf der zweiten Stufe (T. 22).

47 Vgl. Takt 23. Die Subtilität des Übergangs ist auch hier wieder frappierend: Der Anstieg der beiden Violinen von $c^{2}$ (T. 26.1.) über tief $\operatorname{des}^{2}$ (T. 26.3) nach $\operatorname{des}^{2}$ (T. 28.1.) wird durch die vorübergehende Überlappung von $c^{2}$ und tief $d e s^{2}$ um zwei zusätzliche Zwischenschritte ausgedehnt.

48 Der neue Zentralton des erscheint in beiden Oktavlagen zunächst sul ponticello, die übrigen Töne sul tasto, das vorhaltsähnliche Glissando der Viola (tief $C^{2}-C^{2}$ ) zusätzlich im tremolo Dynamisch entspricht dem eine weitere, spannungsvolle Zurücknahme.

49 Nicht nur durch die Akzente, sondern auch durch die zweimalige `Auflösung ‘ von tief $c^{2}$ nach $c^{2}$ (Vla., T. $29 \mathrm{f} ., 31 \mathrm{f}$.)

50 tief $d$ T. 40-41.1; $d$ in T. 44.2.

51 Der diatonische Klang tief a - tief $d^{2}-$ tief $d e s^{3}$ (T. 37) ist zwar aus tonaler Sicht insignifikant und wird durch $c^{3}$ sofort 'gestört; dennoch erinnert die Konstellation tief $a^{1}$ - tief des $^{3}$ im Vorfeld eines Unisono (T. 39f., >Auflösung von tief $d e s^{3}$ nach tief $d^{3}$ ) an eine Kombination aus Diskant- und Bassklausel. - T. 45 klingt im Anschluss an die 'Vorhaltsauflösung` in T. 42 f. (VI. 2) wie ein verzerrter Quartvorhalt. 


\section{‘dramatis persona}

Resümiert man, was sich als Hauptkomponenten dieses Quartetts bisher herauskristallisiert hat, dann wird deutlich, dass der Begriff ,Exposition` nicht nur in seiner übertragenen, musikalisch-technischen, sondern durchaus auch in seiner ursprünglichen, dramatischen Bedeutung angemessen ist - nämlich als Vorstellung des Tons bzw. Klangs als shandelnder Person

1. Der aus dem Einzelton entwickelte Ton bzw. Klang präsentiert sich als ein vielschichtiges und pulsierendes Ganzes, das sich, auch ohne dass sich sein Zentrum bewegte, in ständiger Veränderung befindet, das sich (als Ganzes oder in seinen Schichten) verengen und verbreitern, verschärfen und abdunkeln kann, dessen Pulsation sich beschleunigen und verlangsamen, vibrieren, pochen, zittern oder (nahezu) erstarren kann.

2. Als (von Abschnitt zu Abschnitt wechselnder) `Normalzustand erscheint deshalb nicht der liegende (und 'gerade $`$ ), sondern der sintern bewegte Ton. Auslenkungen dieses je ımittleren Zustandes in die eine oder andere Richtung sind demgegenüber Spannungszustände: Eine Verringerung oder ein Aussetzen der internen Bewegung empfinden wir als Stocken, eine merkliche Beschleunigung als Erregung. Häufig sind es entscheidende diastematische Veränderungen, Störungen oder `Ereignisse`, in deren Umfeld derartige Stockungen oder Beschleunigungen eintreten - sei es im Sinne eines Reagierens, sei es im Sinne einer bangen Vorerwartung.

3. Die Heftigkeit der geschilderten Reaktionen verleiht dem Geschehen eine dramatische bzw., da es sich um ein sinneres` Geschehen handelt, eine psycho-dramatische Komponente.

4. Grundfigur des Quartetts wie seiner Exposition ist der Anstieg. Die Stufen des mikrotonalen Anstiegs folgen (in abnehmendem Maße) dem Modell Setzung - Störung und Ausgleichsbewegung - Verlagerung. Da die einzelnen Phasen dieses Modells durch eine begrenzte Auswahl an (wiederkehrenden) Gesten dargestellt werden, entsteht der Eindruck von Zyklizität - einer Zyklizität freilich, die durch die übergreifende Entwicklung (Verbreiterung und Teilung), durch die Aufnahme immer neuer Komponenten in den Zyklus und durch die Subtilität im Detail allem Mechanischen entgeht.

\section{Erregendes und retardierendes Moment, Vorwegnahme}

(Formteil B, T. 46-112)

\section{Überblick}

War die lineare Entwicklung der `Exposition` vergleichsweise stringent (abgestufter Anstieg von tief $c$ nach $d$ ), so bleibt sie in Formteil B auffallend zurückhaltend, ist streckenweise sogar explizit retardiert. Die Energie scheint sich vorübergehend vollständig ins Innere des Klangs zu verlagern; ein lebhaftes `Flirren` setzt ein, dessen Unterbrechung an zwei Stellen als Innehalten um so spürbarer wird. Die satztechnischen Komponenten 
aber, die hier eingeführt werden, sind dieselben, die später auch die Entwicklung zum Höhepunkt (und die Peripetie) vorbereiten; der Höhepunkt selbst wird, wie vage auch immer, klanglich vorweggenommen.

Die Zyklizität ist hier bereits stärker ausgeprägt als im ersten Formteil. Ohne dass wörtliche Übereinstimmungen zu erkennen wären, lassen sich doch zwei deutlich analoge Unterabschnitte ausmachen:

\begin{tabular}{|l|l|l|l|l|}
\hline Formteil & Unisono & $\begin{array}{l}\text { Intervall- } \\
\text { spreizung }\end{array}$ & Oszillation & $\begin{array}{l}\text { d als Störton, } \\
\text { Retardation }\end{array}$ \\
\hline B1 & $\begin{array}{l}\text { T. 40 }(\text { tief } d), \\
\text { T. 42.2, T. 46 }(\text { d })\end{array}$ & T. 46-50 & $\begin{array}{l}\text { T. 50-62 } \\
\text { hoch } \mathrm{cis}^{2} / \mathrm{e}^{2} \text { (T. 50) bzw. } \mathrm{cis}^{2} / \mathrm{es}^{2} \text { (T. 55) }\end{array}$ & T. 63-74 \\
\hline B2 & T. 74 $($ d $)$ & T. 74-80 & $\begin{array}{l}\text { T. 77.3-89 } \\
\mathrm{C}^{2}-\text { tief } \mathrm{e}^{2} \text { (T. 80) bzw. } \mathrm{cis}^{2}-\mathrm{e}^{2} \text { (T. 86) }\end{array}$ & T. 90-112 \\
\hline
\end{tabular}

Tabelle 4: Scelsi, viertes Streichquartett, Übereinstimmungen zwischen den Formteilen B1 und B2

Ausgangspunkt ist in B1 wie in B2 ein Unisono-d. Dieses steilt sich in einer Spreizbewegung in zwei Stimmen-Stränge im zweigestrichenen Register, deren Abstand zwischen einem Ganzton und einer kleinen, zuweilen auch großen Terz schwankt. Dabei präsentiert sich der höhere Strang als oszillierend (und als konkrete Tonhöhe kaum fassbar) - er besteht in der Regel aus mehreren mikrotonal benachbarten Linien und wird durch eine Kombination aus Trillern, Bariolage, Tremolo und Frequenzvibrato in ständiger innerer Bewegung gehalten -, der tiefere als eher liegend - er besteht überwiegend aus geraden, mikrotonal nicht oder wenig getrübten Tönen und wird in unregelmäßigen Abständen durch seine Unteroktave abgestützt. Der sstörende` Wiedereintritt eines einzelnen $d^{1}$ in Takt 63 bzw. Takt 90 (bzw. nochmals in T. 99) bringt die oszillierende Bewegung zum Erliegen und löst eine Wiederannäherung der beiden Stränge aus, die schließlich in ein weiteres Unisono mündet ( $d$ in T. 74, e in T. 111). ${ }^{52}$ Im Vorfeld der Wiederannäherung wird der liegende Strang beide Male in die dreigestrichene Oktave versetzt (T. 61 und 95, vgl. Reduktion in Anhang 1).

Die Veränderungen von B2 gegenüber B1 scheinen zunächst minimal: Der oszillierende Strang wird (von tief $\mathrm{e}^{2}$ nach $\mathrm{e}^{2}$ ) angehoben statt (von $\mathrm{e}^{2}$ nach $\mathrm{es}^{2}$ ) abgesenkt, und der durchschnittliche Abstand zwischen liegendem und oszillierenden Strang vergrößert sich vom `Ganzton` (B1) zur skleinen bzw. ıneutralen` Terzı (B2). Doch erfolgt die Annäherung zwischen den beiden Strängen in diesem Fall einseitig als Anhebung des ursprünglich liegenden Strangs nach $e^{2}$ (T. 95-106 bzw. T. 111), so dass der Ton $\mathrm{cis}^{2}$ mit Beginn von C1 (T. 113) gleichsam sunverbraucht ‘ wieder eintreten kann. Zudem steuern vorübergehende zusätzliche Töne eine Reihe von Ereignissen bei, die mit einer Kombination aus stonaler Andeutung und Zurücknahme, bzw. allgemeiner, aus Harmonizität und Inharmonizität, bereits zentrale Stationen von Formteil C (bzw. sogar dessen prozessuale Grundfigur) vorwegnehmen. So wird in Takt 80 die neutrale Terz $c^{2}-$ tief $e^{2}$ von 2. Violine und Violoncello durch ein hohes gis ${ }^{3}$ der 1. Violine zu einem Klang ergänzt,

52 Vorwegnehmend, aber noch nicht in `Reinform`, wird der Ton $d$ in T. 70 erreicht. 
der zwischen einem übermäßigen Dreiklang und einem As-Dur-Sextakkord ambivalent ist, zwei Takte später (T. 82) wird ein Portamento von $d_{i s^{2}}$ nach $e^{2}$ durch ein flüchtiges $g^{1}$ zum C-Dur-Quartsextakkord ergänzt. Die tonale Reminiszenz wird jedoch sofort zurückgenommen, wenn in den Takten $83 \mathrm{f}$. das Rahmenintervall $c^{2}-e^{2}$ durch einen mikrotonalen Cluster aufgefüllt und angeraut wird. ${ }^{53}$ Ähnlich tritt beim Wechsel zum Liegeton $c i s^{2}$ (T. 86) für einen Moment die mikrotonal kaum getrübte kleine Terz $c i s^{2}-e^{2}$ hervor; ${ }^{54}$ auch sie wird in Takt 90 durch den aus Takt 63 bekannten `Störton` $d^{1}$ getrübt.

An der Schwelle: Takt 90-112

Der nun folgende Übergang nach Formteil C (T. 90-112) ist als Phase des Retardierens ungleich länger als der analoge Abschnitt in B1 (63-74) und sei hier, um seiner eigenwilligen Dramaturgie willen, etwas eingehender analysiert. (Die beteiligten Satzschichten sind in Beispiel Anhang 2 durch verschiedene Formen der Umrahmung markiert.)

Die Passage lässt sich wie folgt gliedern:

\begin{tabular}{|l|l|}
\hline T. 90-99 & Störton $d^{1}$, kurze Anhebung und Zurücknahme; tonale `Vor-Andeutungen` \\
\hline T. 99.3-105 & Störton $d^{2}$, zweite gedehnte Anhebung \\
\hline T. 105.3-115 & Liegeton $e^{2}$, Dominant-Allusion; `Erwartung \\
\hline T. 116-119 & 'Tonika ‘ A-Dur und Beginn von C \\
\hline
\end{tabular}

Tabelle 5: Scelsi, viertes Streichquartett, Übergang zu Formteil C

Mit Eintritt des Störtons $d^{1}$ in der Viola wird die zuletzt bestimmende Konstellation aus liegendem $\mathrm{cis}^{2}$ und oszillierendem $\mathrm{e}^{2}$ (vgl. die graue Unterlegung im Beispiel Anhang 2) um einen weiteren Strang angereichert. An die Stelle der oszillierenden Bewegungen treten langsame externe Bewegungen, die sich aufgrund der geraden Tongebung umso empfindlicher bemerkbar machen. In einer vorläufigen Klimax (T. 94) wird dabei erstmals der Ton $f^{2}$ und damit die große Terz zwischen den beiden (ursprünglichen) Strängen erreicht ${ }^{55}$, hier angereichert um den sschiefen Ganzton hoch $d^{1}$. Eine leichte Anschärfung durch crescendo und con legno treibt in Takt 95 aus dem cis-Strang ein mikrotonal sverunreinigtes` hoch $c^{3}$ der 1 . Violine hervor - verzerrte Oktave der Töne $c i s^{1}$ und $c i s^{2}$, die im Folgenden ausgeblendet werden. ${ }^{56}$

Die nun folgende, sehr zurückgenommene Passage (T. 96-99) ist bestimmt durch mikrotonale Schwankungen der 1. Violine um diesen Ton hoch $c^{3}$, welche durch das ab Takt 95.3 liegende $e^{2}$ und Einzeltöne der Unterstimmen wechselhaft beleuchtet werden.

53 Vgl. die sVerklumpungen in C1, Takt 149-155 und in C2, Takt 184-192.

54 Mit fortissimo und forte setzen sich $\mathrm{Cis}^{2}$ und $\mathrm{e}^{2}$ gegenüber allen mikrotonalen Schattierungen durch; vgl. jeweils die Anfänge von C1-3.

55 Es handelt sich um die zweite große Terz nach T. 82 (s.o.)

56 Ein analoger Registerwechsel - von von cis $^{1 / 2}$ nach cis $^{3}$ - begegnet in B1 in T. $60 \mathrm{f}$., also bereits vor Eintreten des s Störtons` $d{ }^{1}$. 
Dabei deutet sich in Takt 97 mit a und hoch des ${ }^{3}$ für einen kurzen Moment ein verzerrter A-Dur-Dreiklang an.

Wenn der Ton $\mathrm{cis}^{3}$ schließlich wieder in mikrotonal ungetrübter Form erklingt (T. 99.1), dann ist damit nicht nur einer der dynamischen Tiefpunkte des Quartetts erreicht, sondern auch ein weiteres störendes $d^{(2)}$ in Viola und Violoncello (T. 99.3) und damit eine zu Takt 90 bzw. 63 analoge Position. Auch hier löst dieser Ton eine Bewegung dreier Stränge nach oben aus. Der cis $^{3}$-Strang senkt sich zunächst in Takt 101 nach $\mathrm{C}^{3}$ und steigt dann sehr langsam bis hoch $\mathrm{Cis}^{3}$, wo er in Takt 106 zum Halten kommt. Der $e^{2}$-Strang wird nach einer vierteltönigen Anhebung (T. 103) ausgeblendet. An seine Stelle rückt der von $d^{2}$ ausgehende Strang, der, von Anfang an dynamisch im Vordergrund, mit Erreichen des $e^{2}$ in Takt 106 alle anderen Stimmen übertönt. Der gesamte Vorgang wirkt extrem zerdehnt - vielleicht gerade weil ab Takt 101 alle Schichten nahezu durchgängig ansteigen, d. h. die Tendenz eindeutig, aber zugleich spürbar zurückgehalten ist.

Kurz vor Erreichen des $e^{2}$ setzt - dynamisch bereits völlig überschattet - eine Art Imitation zwischen den glissandierenden Stimmen ein, die in mehrfacher Hinsicht aus dem Rahmen fällt:

1. Zum ersten Mal kommen hier die bislang kaum bzw. gar nicht verwendeten Register der kleinen und großen Oktave zum Einsatz.

2. Mit den Glissandi von Viola, Violoncello und 1. Violine wird innerhalb von fünf Takten das vierteltönige Total einmal durchmessen.

3. Die Takte $108 \mathrm{f}$. umspielen kaum verhüllt einen Dominantseptakkord $\mathrm{E}^{7}$, der von dem Liegeton $e$ in 2. Violine und Violoncello eingerahmt wird. Dabei treffen im Zuge einer Spreizbewegung zwischen Violoncello und Viola scheinbar zufällig die Akkorde C-Dur und $\mathrm{E}^{7}$ unmittelbar aufeinander (T. 109). Ein Ritenendo - die einzige vorgeschriebene Tempoänderung im gesamten Quartett - unterstreicht diese in ihrer Dichte von Simultanereignissen singuläre Stelle. Wenn irgendwo in diesem Quartett von einer Referenz an den klassischen Quartettsatz gesprochen werden kann, dann in dieser zwar freien, aber im gegebenen satztechnischen Umfeld doch sehr deutlichen $>$ Imitations.

Der Einsatz der 2. Violine in Takt 109 leitet das Ende dieses >Exkurses und das Einmünden aller Stimmen in den e-Strang ein. Sukzessive werden nun in den Takten 113, 116 und 117 - und das heißt ziemlich genau in der Mitte des Stückes - die Töne eines zwar verzerrten, aber unmissverständlichen A-Dur-Dreiklangs aufgeschichtet; die einzelnen Stränge werden wieder in die vorige oszillierende Bewegung versetzt. Eine Phase der Instabilität, der scheinbaren Richtungslosigkeit und der Zurückhaltung wird abgelöst von einer Phase der dichten internen Bewegung, des `Nach-oben-Treibens` und der Zentraltönigkeit (als welche sich Teil C als Ganzes präsentiert).

Die tonalen Allusionen des soeben besprochenen Abschnitts bilden eine steigernde Variantenkette, die mit ersten, vorsichtigen Andeutungen in den Takten 80/82 ( As-Dur $/>C$-Dur $<$ beginnt, in der verzerrten Durterz cis- $f$ und dem verzerrten A-DurDreiklang der Takte 94 und 97 fortgesetzt wird und in den nur leicht verzerrten Durdreiklängen der Takte 116-119 (A-Dur) ihr vorläufiges Ziel findet - das seinerseits durch den 
kurzen, aber sfundierteren` B-Dur-Akkord in Takt 167 `überboten` wird. Die Großterzrelationen, die sich dabei herauskristallisieren, ergeben sich bei einem Komponieren mit Liegetönen zwangsläufig: Geht es darum, einen über weite Strecken stabilen tieferen Ton und einen höheren Ton, der sich im Abstand einer kleinen bzw. großen Terz bewegt, zum Dreiklang zu vervollständigen, so bleibt letztlich nur die Ergänzung einer weiteren Terz nach oben oder unten:

\begin{tabular}{|l|l|l|}
\hline Akkorde bzw. Zweiklänge & Liegeton & Takte \\
\hline 'As-Dur - ‘C-Dur & c & 80,82 \\
\hline cis- $f$ - A-Dur & cis & 94,97 \\
\hline A-Dur - Cis-Dur & cis & $116-119 ;(121 \mathrm{f} ., 123$ f.) 129.3 \\
\hline$d-f$ - B-Dur & $d$ & $158 \mathrm{ff} ., 167$ \\
\hline
\end{tabular}

Tabelle 6: Scelsi, viertes Streichquartett, Großterzrelationen

Dass die tonalen Allusionen des soeben besprochenen Abschnitts keine `Zufallsprodukter sind, sondern gezielt herbeigeführte formale Attraktionen bzw. (im Falle von T. 116 ff.) Höhepunkte, zeigt sich

1. daran, dass zumindest die vollständigen Dreiklänge (C-Dur, A-Dur, B-Dur sowie der vage As-Dur-Dreiklang) durch Zusatztöne überhaupt erst ermöglicht werden,

2. an der langfristigen Dramaturgie des Innehaltens und der vorsichtigen Vorwegnahme,

3. an der unmittelbaren Herbeiführung des A-Dur-Dreiklangs: mit einem aus dem gesamten satztechnischen Kontext herausfallenden `Dominant-Orgelpunkt‘, einem allmählichen Einmünden aller Stimmen in den Ton e und schließlich

4. an der schrittweisen Einführung der Dreiklangskomponenten in den Takten 111, 113 und 116. Dabei werden nicht nur tonale Hörerinnerungen einer mikrotonal orientierten Form-Dramaturgie nutzbar gemacht, sondern auch umgekehrt dem Durdreiklang (der im Übrigen nie völlig unverzerrt erklingt) gerade in einem ihm völlig fremden Kontext etwas von seinem früheren Glanz zurückgewonnen. ${ }^{57}$

\section{Variable und steigernde Zyklen (Formteil C, T. 113-231)}

Deutlicher und umfassender noch als Formteil B arbeitet $C$ nach dem Prinzip ıWiederholung und Steigerungs. Wiederholt und variiert werden hier nicht nur einzelne Komponenten, die mal in dieser, mal in jener Form erscheinen können, sondern Stimmauszüge längerer Partiturausschnitte, deren Nähe oder Ferne zum `Original bzw. deren unterschiedliche Einbettung in den harmonisch-satztechnischen Kontext sie zu Stationen eines dramatischen Verlaufs macht:

57 Auf eine ähnlich subtile Weise begegnen dreiklangsähnliche Gebilde in Scelsis Anahit. Murail deutet solche Phänomene als vierteltönig verzerrte Dreiklänge (2005, 185). 


\begin{tabular}{|l|l|l|l|}
\hline C1 & C2 & C3 & \\
\hline T. $113-157$ & T. $158-195$ & T. $196-226$ & Umfang des gesamten Formteils \\
\hline T. $135-157$ & T. $170-192$ & & Zitierter Abschnitt aus C1 und dessen Variante in C2 \\
\hline T. $129-144$ & & T. $209-224$ & Zitierter Abschnitt aus C1 und dessen Variante in C3 \\
\hline T. $135-144$ & T. 170-179 & T. $215-224$ & Kernabschnitt, der von C2 und C3 aufgegriffen wird \\
\hline
\end{tabular}

Abbildung 7: Scelsi, viertes Streichquartett, wiederkehrende Stimmauszüge innerhalb von Formteil C

\section{Steigerung (C1, T. 113-157)}

Das in Takt 113 eingetretene cis $^{2}$ bleibt als Liegeton bis Takt 134 erhalten. Mit ihm als modalem Zentrum beginnt nun der e-Strang weiter nach oben zu treiben. Dabei werden gerade zu Beginn die modalen Qualitäten ${ }^{58}$ einzelner Stufen gezielt ausgespielt. So wird der Übergang von der kleinen zur großen Terz in mehreren Anläufen ızelebriertı, das Erscheinen der Oberquarte fis ${ }^{2}$ löst die Unterquarte hoch $g^{1}$ aus und damit einen schiefen Quartenklang; die vorübergehende Absenkung nach $f^{2}$ in Takt 129 wiederum löst einen zwar kurzen, aber deutlichen Cis-Dur-Quartsextakkord aus. Damit kristallisiert sich zwischen den Takten $116 \mathrm{ff}$. und 129 eine analoge Terzverwandtschaft wie zu Beginn von B2 (T. 80 und 82) - mit dem Unterschied, dass dort die Dreiklänge As-Dur und C-Dur nur angedeutet wurden, während hier A-Dur und Cis-Dur unmissverständlich sind.

Parallel dazu wird der bewegliche Strang durch heterophone Verdopplung, dynamische Steigerung und Triller schrittweise intensiviert. Nach Wegfall des Liegetons in Takt 134 erfasst der bewegliche Strang die dreigestrichene, schließlich auch die eingestrichene Oktave. Beide Register werden zunächst nur sangerissen`, ehe sie kontinuierlich miteinbezogen werden. ${ }^{59}$ Scheitelpunkt dieser Bewegung ist der Ton $a^{3}$ in den Takten $139 \mathrm{f}$., der als neuen Liegeton $\mathrm{es}^{2}$ nach sich zieht. ${ }^{60}$ Die nun folgende Absenkung ${ }^{61}$, die - mit gehäuften Tremoli, Schwebungen im fortissimo und Spieltechniken wie sul ponticello, con legno und grattato alle Züge der Verzerrung trägt, mündet mit Takt 148 in eine clusterähnliche `Verklumpung;; ein Lagenwechsel führt in Takt 150 zur Sexte ges ${ }^{1}$-es², die nach vorübergehender Anhebung ebenfalls in eine Verklumpung mündet und in Takt 158 nach abermaligem Lagenwechsel von der mehrfach oktavierten Sexte $f$ - $d^{1}$ abgelöst wird, die Formteil C2 einleitet.

58 Mit den Begriffen ımodales Zentrum` und `modale Qualität` wird dem Umstand Rechnung getragen, dass wir die wechselnden Intervalle zwischen beweglichem Strang und Zentralton bei aller Flexibilität bzw. Instabilität selten als ıneutrak wahrnehmen, sondern - zumindest von der (`Dur<- oder ,Molk-)Terz ab aufwärts - meist (auch) tonal bzw. modal, d. h. vor dem Hintergrund unserer (durmolltonal bzw. modal geprägten) Hörerfahrung.

59 Siehe z. B. das wiederholte Anreißen von $\mathrm{fis}^{3}$ in den Takten $128-133$ sowie von gis $^{1} / \mathrm{as}^{1}$ in den Takten $137 \mathrm{f}$. und $140 \mathrm{f}$.

60 Der a-Strang verengt sich beim Übergang zu Takt 140 zu as-a.

61 Die Absenkung macht sich zunächst vor allem als eine Verbreiterung und Häufung der von unten ausholenden Bewegungen bermerkbar. 
Bemerkenswert an dieser Entwicklung ist, dass der Übergang zwischen Intensivierung und Verzerrung nahezu unmerklich ist. Beide sind Teil ein und desselben Steigerungsprozesses. Auch die diastematischen Vorgänge des Hinabziehens und der Verbreiterung werden noch während des Plateaus (T. 139-145) unmerklich eingeleitet (ab T. 141).

\section{Höhepunkt und Peripetie (C2, T. 158-195)}

Mit Takt 158 geht die Intensität, die sich zuletzt völlig auf den tremolierten Cluster (um den Ton e) konzentrierte, auf die mehrfach oktavierten Tonstufen $>F$ < und $>D$ < über. Auf die Verengung (tonräumlich wie auch hinsichtlich der Tonqualitäten) folgt die Weitung; auf das Zittern der Tremoli das ruhigere Strömen der >chorischen` Einsätze ${ }^{62}$; auf die unruhige Beweglichkeit des an- und absteigenden Zentraltons dessen vorübergehende Stabilisierung; eine Intensität, die auf extremer Inharmonizität basiert - auf intervallischer und zeitlicher Verdichtung ins Geräuschhafte -, weicht einer Intensität, die zu einem großen Teil auf dem Anspielen (und mikrotonalen Verfremden) tonaler und vortonaler Hörerinnerungen basiert - und auf einem fast hypnotischen Insistieren auf dem Zentralton $d^{63}$

Die Analogie, aber auch die Unterschiede zum Beginn von C1 sind unüberhörbar: An die Stelle der shellen Terz cis-e tritt die dunklere, mehrfach oktavierte Sexte $f$ - $d$; wie zuvor der Ton $e^{2}$, so wird hier der Ton $f$ durch seine beiden mikrotonalen Nachbartöne in Schwebung versetzt bzw. vorhaltsähnlich ausgelenkt. ${ }^{64}$ Der B-Dur-Dreiklang in Takt 167 erklingt zwar vergleichsweise kurz und `beiläufig`, aber zugleich intonationsmäßig klarer und 'fundierter (in weiter Lage) als die A-Dur-Dreiklänge der Takte $116 \mathrm{ff}$. Auch das Vorfeld der beiden Dreiklänge ist völlig andersartig: dort das sehr allmähliche Einmünden in den Ton e und die zwar versteckte, aber doch hörbare Dominant-Tonika-Relation, hier die Zuspitzung zum Cluster (ebenfalls um e) und nicht die Spur einer tonalen Relation. Ist dort - durch das dominantische Vorfeld - in den Tönen e und cis von Anfang an der Ton $a$ als Möglichkeit enthalten, so werden $d$ und $f$ hier zunächst tonal unspezifisch, dann als Bestandteile des `dorischen Tetrachords` $d-e-f-g$ (T. 162-165) ausgebreitet, ehe sie als Terz und Quinte eines B-Dur-Dreiklangs hörbar werden. ${ }^{65}$ Wird dort - nach einer Phase

62 Liegende Töne gewinnen durch überlappende Einsätze in verschiedenen Instrumenten und Saiten nicht nur immer erneut an Start-Energie, sondern auch an rhythmischem Impuls und klanglicher Lebendigkeit.

63 Dieser wird erst deutlich nach Beginn von C3 wieder losgelassen (T. 208).

64 Einzige Ausnahme: 1. Violine, T. $158 \mathrm{f}$.

65 Das B im Violoncello, das die Sexte $f$ - $d$ endlich zum B-Dur-Dreiklang ergänzt, scheint für Scelsi tatsächlich der Höhepunkt des Quartetts gewesen zu sein. Wie Franco Sciannameo berichtete, verfolgte Scelsi die Proben zur Ersteinspielung (Herbst 1965) zumeist vom Nebenzimmer aus und kümmerte sich mehr um den »ästhetischen Gesamteindruck«, während sein Assistent und Ghostwriter Vieri Tosatti mit »unfehlbarem Ohr« die eigentliche Probenarbeit übernahm. Bemerkenswert ist nun die blumige Sprache, mit der ein vergleichsweise simples Phänomen weniger benannt als wortreich umschrieben - und entsprechend lange gesucht wird: »| remember him saying, 'There is an arch somewhere in the piece which I want you to reach to; it should sound like the culmination of a chorale. But he was never clear where in the piece it was going to occur, and the notation in the score seemed unable to identify it. One evening the search for the elusive chorale leading to the quartet's ıgolden moment finally revealed it, as Scelsi exclaimed from the other room, sÉ qui, é 
des Zögerns und der Zurückhaltung - ein vorsichtiger Neubeginn, der Beginn der zweiten Hälfte des Quartetts gesetzt, so nimmt diese Stelle - als der eigentliche Höhepunkt des Stückes - die Intensität und Tragik der vorangegangenen Steigerung und des ersten 'Scheiterns in sich auf. Und es entspricht dieser veränderten Position, dass von der nun folgenden, ansteigenden Passage die ersten, noch vergleichsweise zurückhaltend instrumentierten Schritte übersprungen werden. ${ }^{66}$ Ist die diastematische Entwicklung von C1 bogenförmig, so ist die von C2 plateauähnlich. ${ }^{67}$

Aufschlussreich ist nun, wie die übernommenen Partien ausgewählt und durch einen abgestuften Transpositionsmodus der neuen Situation angepasst werden:

1. Der Abstand zwischen Zentralton und beweglichem Strang wird von vornherein verkleinert, indem jener um einen Halbton höher liegt, dieser aber um einen Halb- bzw. Dreiviertelton nach unten versetzt wird.

2. Die Analogie zu C1 beginnt erst ab dem Moment, ab dem auch dort das dreigestrichene Register kontinuierlich beteiligt ist ${ }^{68}$, d. h. der Anstieg eine gewisse Intensität, aber zugleich nahezu seinen Höhepunkt erreicht hat. ${ }^{69}$

3. Der Einstiegston $g^{3}$ ist vom Hochton nur mehr einen Viertelton entfernt (tief $a s^{3}$, T. 176 ff.). ${ }^{70}$

4. Der Abstieg wird verzögert und abgeschwächt, indem sich das Transpositionsintervall sukzessive vom Halbton bzw. Dreiviertelton ${ }^{71}$ über einen Viertelton (T. 183) auf 0 (T. 185) verkleinert.

Im Beispiel Anhang 3 sind für die Art, wie einzelne Stimmpartien aus C1 in den neuen Kontext von C2 eingebettet werden, die Takte 136-141 und 171-176 gegenübergestellt: Während in den Anfangstakten von C2 - mit Ausnahme des flüchtigen B-Dur-Akkords - durchweg $f$ im Bass lag (als Terz eines latenten d-Moll), fungiert in diesem Abschnitt durchweg der >Grundton $d^{1}$ als Orgelpunkt, streckenweise auch (klein) $d$, vielfach verstärkt durch ein liegendes $d^{2}$ (im Beispiel alle nicht umrahmten Töne). Da zudem bis einschließlich Takt 177 auch die übrigen Töne des `dorischen Tetrachords` sim Spiel bleiben` (grau unterlegt), ist die Zahl der aus C1 übernommenen Stimmpartien (umrahmt) naturgemäß zunächst begrenzt. ${ }^{72}$ Vollständig übernommen werden, mitunter in verein-

qui! «. It was there all along, in bar 167, triggered by a low pedal note in the cello, played fortissimo. We just were not getting enough into the centre of the sound to strike the right note - we had not yet entered into the illusive third sonic dimension about which Scelsi was so adamant." (Sciannameo 2001, 24).

66 Entsprechend den Takten 120 bis 135 bzw. einem Anstieg von einer kleinen Terz.

67 Der ebenfalls plateauähnliche Charakter der Takte 139-145 (s. o.) ändert nichts an der bogenförmigen Gesamtanlage von C1.

68 Ab Takt 135 fällt zudem der Liegeton weg und wird erst in T. 140 durch es ${ }^{2}$ sersetztı.

69 Ausgespart wird ein Abschnitt, in dem der bewegliche Strang um eine kleine Terz steigt.

70 Die vorübergehende Wechselnote $a s^{3}$ in Takt 174 ist singulär.

71 Dies nur vereinzelt, so z. B. die Hochtöne $g^{3}$ in den Takten 175 und 180 (gegenüber T. 140 und 145). 
fachter Form, die Stimmen des dreigestrichenen Registers ${ }^{73}$, während der in C1 stark heterophone Strang des zweigestrichenen Registers durchweg auf eine Stimme verengt wird. ${ }^{74}$ Die Töne des eingestrichenen Registers werden teils ausgespart, teils metrisch versetzt, um die Töne des `dorischen Tetrachords` durchzulassen. Beinahe shymnisch ist (in diesem Kontext) das Melodiefragment im Violoncello, das - nach ersten Ansätzen in den Takten 171-174 - mit den Takten 175-177 >durchbricht . ${ }^{75}$ Das Transpositionsintervall schwankt zwischen einem Halb-, Viertel- und Dreiviertelton unterhalb der Originaltonhöhe, letzteres (bis T. 182) vor allem, wenn es darum geht, den Ton $g^{2 / 3}$ als Grenzton nicht zu überschreiten. ${ }^{76}$ Durch die Flexibilität hinsichtlich des Transpositionsintervalls bleibt das zu Beginn ausgebreitete `dorische Tetrachord ‘ auch dann noch prägend, wenn über die aus C1 übernommenen Partien hinaus nur noch der Zentralton $d$ gehalten wird.

In den (im Anhang nicht wiedergegebenen) Takten 178-186 (entsprechend T. 143$151)^{77}$ wird praktisch der vollständige Tonsatz aus C1 übernommen. Bereits die analogen Takte in C1 markieren einen Umschlag der diastematischen und klanglichen Entwicklung: Im Anschluss an den diastematischen Wendepunkt in Takt $140^{78}$ setzt dort durch intensive Tremoli im Vierteltonabstand und Verbreiterung des oszillierenden Strangs zum bewegten Cluster eine schrittweise Verzerrung ein. Damit wird die seigentlicher Peripetie dieses Satzes eingeleitet. ${ }^{79}$ Durch die sukzessive Verkleinerung des Transpositionsintervalls (und damit auch des Abstiegs) ist die beginnende Verzerrung hier noch unterschwelliger als in C1. Anschließend zwingen eine breitere lagenmäßige Streuung des Zentraltons im Violoncello und die Versetzung des letzten Einwurfs im dreigestrichenen Register ins zweigestrichene ${ }^{80}$ zu einer erneuten Reduktion gegenüber der Parallelstelle. Die Verklumpung (tremolierter Cluster) fällt deshalb im Vergleich fast milde aus.

72 >Dorische` Fragmente in C2 (die meisten von ihnen klingen eher wie ein Ausschnitt einer mollpentatonischen Skala, da der Ton e wegfällt): Takt 163, 1. Violine: $g^{1}-f^{2}-g^{1}$; Takt 165, Viola: $f^{3}-g^{3}$; Takt 167, 2. Violine: $f-d^{2}$. Nach Beginn der Analogie zu C1: Takt 171-76, Violoncello/1. Violine: $d^{1}-e^{1}-d-e^{1}-$ $f^{1}-\left[g^{1}\right]-f^{1}-d^{2}-g^{1}-f^{1}$ (in []: 1. Violine); Takt 180, Viola: $f^{1}-g^{2}$ (rhythmisch mit VI. 2 T. 145 übereinstimmend, aber oktavversetzt und intervallisch augmentiert).

73 Dessen Stimmen werden im Wesentlichen direkt aus C1 übernommen. Die deutliche Vereinfachung in der 1. Violine von $174 \mathrm{ff}$. gegenüber $139 \mathrm{ff}$. dürfte ebenfalls durch besagtes Melodiefragment motiviert sein, an dem neben dem Violoncello auch die 1. Violine beteiligt ist.

74 So fasst die Viola in den Takten 171-175 die Stimmen von 2. Violine, Viola und Violoncello der Takte 136-140 zusammen, indem sie vom Violoncello Rhythmus und Intervallik und von der Viola den durchgehenden Triller übernimmt.

75 Möglicherweise ein Anlass für Scelsis Choral-Assoziation (vgl. Anm. 65).

76 Was nicht heißt, dass die Töne tief $a s^{2} /{ }^{3}$ und sogar $a s^{2} / 3$ nicht hin und wieder von einer Einzelstimme gespielt würden.

77 D. h. ab dem Moment, wo das sdorische Tetrachord ` auf das gehaltene $d^{1}$ des Violoncello reduziert ist - und selbst dieses gerät in den Takten 183-185 ins Schwanken.

78 Takt 140 ist mit einer Verengung des oszillierenden Strangs auf den Bereich zwischen as und a Hochpunkt von C2. Anschließend werden die zuvor ausgeblendeten tieferen Töne wieder eingeführt.

79 Zur Annahme mehrerer, unterschiedlich gewichteter, Peripetien (Peripetie I entspräche den Takten 141-157) vgl. Résumé.

80 1. Violine, T. $191 \mathrm{f}$. , entsprechend $156 \mathrm{f}$. 
Der Beginn von C3 gleicht eher einer sukzessiven Ausfilterung, einem Nachklang als einem Neubeginn. Zwar wird mit dem mehrfach akzentuierten $f$ (im Zusammenhang mit d) ab Takt 193 eine Analogie zum Beginn von C2 hergestellt. Der beibehaltene Zentralton

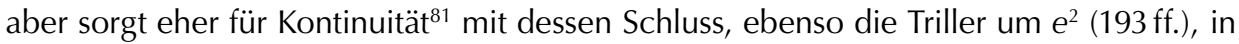
denen zunächst noch ein Teil von dessen Oszillation nachschwingt. Dennoch ist die Intensität dieses Abschnitts von völlig anderer Art als die, die C2 prägte: Nach den Tremoli fallen ab Takt 197 auch die Triller weg; der Tonraum verengt sich vorübergehend auf den Bereich zwischen $d^{1}$ und fis $^{2}$ (T. 193.3-201.1). Einer zzarten ${ }^{82}$, nach zerdehntem Anstieg um die Durterz fis $^{2}$ schwankenden $>$ Melodie im zweigestrichenen Register stehen - in Gestalt massiver, vibratoloser Liegetöne im eingestrichenen Register - die Mollterz $d^{1}-f^{1}$ und $e^{1}$ - gegenüber. ${ }^{83}$ Sowie die Durterz erreicht ist (T. 198), baut sich im eingestrichenen Register ein mikrotonaler Cluster auf (T. 199f.). Beides - das Bedrohungsszenario und die spezielle Setzweise des Molldurklangs ${ }^{84}$ - verleiht dieser Stelle ihren eigentümlichen Charakter: Er signalisiert, dass - dramaturgisch gesprochen - die fallende Entwicklung ihren Tiefpunkt erreicht hat, in dem der Höhepunkt als trübe Erinnerung noch nachklingt.

Wie aus der Reduktion in Anhang 1 ersichtlich, ist die gesamte Passage (bis T. 209, d. h. bis zum Beginn der Analogie zu C1) lagenmäßig als Auffächerung und Verengung konzipiert. Der Takt mit dem weitesten Ambitus (T. 205) markiert zugleich die einzige Stelle (außer T. 198), an der die Durterz ungestört hervortreten kann; ab diesem Moment wird der Zentralton sukzessive ausgeblendet.

Die ansteigenden Takte 209-224 könnte man - in Anlehnung an die erste Komponente im Titel zum Finale des III. Quartetts - als »libération« bezeichnen: als Loslösung vom Zentralton, als Befreiung von 'Schwerkraftı und »Pathos« (der tonalen Erinnerungen), die der eigentlichen »Katharsis« notwendig vorausgehen.

Die gesamte Passage übernimmt im Wesentlichen den Tonsatz der Takte 129-144. ${ }^{85}$ Ausgespart (gegenüber C1) werden jene Takte, in denen der bewegliche Strang zwischen kleiner Terz und Quarte zum Liegeton nach oben drängte (T. 120-128) - deren diastematische `Funktion ist durch die Takte 193-208 letztlich sabgegolten «-, sowie der gesamte Abstieg (T. 146-157). Takt 209 (entsprechend T. 129), der als Scharnier fungiert ${ }^{86}$, lässt mit $f^{1}$ und $e^{2}$ noch zwei Liegetöne des vorigen Abschnitts überhängen; der seigentlich ‘ ${ }^{87}$ fällige Liegeton $c^{2}$ tritt erst in Takt 210 (entsprechend T. 130) ein. Nicht ein Dur-Quart-

81 Die Wiederverstärkung des Zentraltons ist bereits mit Takt 187 durch das Hinzutreten von $d$ und $d^{2}$ eingeleitet.

82 Siehe die Spielanweisung in Takt 197.

83 Hierin besonders extrem: die Takte 197-199 mit ihrem herausgemeißelten $e^{1}$ und der Cluster in Takt 199.

84 `Traditionelk (im Sinne des späten 19. und frühen 20. Jahrhunderts) wäre eine Setzweise mit der Mollterz im höheren Register, die als (erstarrter) Vorhalt (zur Dezime oder None) aufgefasst werden könnte.

85 Die Analogien beginnen teilweise bereits in T. 208/128.

86 Wie bereits teilweise T. 208/128.

87 Im Sinne der Analogie zu T. 129. 
sextakkord (wie in T. 129.3), sondern ein Tritonus zwischen dem neuen Liegeton $c^{2}$ und dem beweglichem Strang (wie in T. 130) beendet damit als erster auffällig abweichender Zusammenklang den Einflussbereich des über 50 Takte beherrschenden Liegetons $d$. Dramaturgisch ließe sich kaum ein sprechenderer Wendepunkt vor dem letzten Anstieg denken als dieses Signal der Bangigkeit.

Durch eine Folge von Transpositionsstufen, die von $-1 / 2$ bis $+1 / 2$ reicht ${ }^{88}$, wird der Anstieg gegenüber der Vorlage in C1 vergrößert, so dass selbst das Plateau gegen Ende in einen weiteren Anstieg umgemünzt wird. Zwischen den Liegetönen (in C1 nur $\mathrm{Cis}^{2}$ und $e s^{2}$ ) entsteht durch Einschaltung einer einzigen zusätzlichen Stufe ( $d^{2}$ in T. 216f.) die quasi chromatische Folge $c^{2}$ (T. 210) - $c i s^{2}$ (T. 212) - $d^{2}$ (T. 216) - es $s^{2}$ (T. 220) $e^{2} / t i e f f^{2}$ (T. 223). Ähnlich wird die (pausendurchsetzte) Tonfolge in der eingestrichenen Oktave durch hoch $g^{1}$ (T. 217-118, Vla. und Vcl.) angereichert; die dabei entstehende, von $f^{1}$ bis $b^{1}$ ansteigende Linie wird allerdings durch die (untransponierten) Takte 219-221 durchbrochen. Darüber hinaus sorgen spieltechnische Veränderungen, Verlängerungen und Zusätze für klangliche Intensivierung. ${ }^{89}$

\section{Katharsis}

Bereits mit den Takten 222-224 verstärkt Scelsi durch leichte rhythmische und spieltechnische Veränderungen eine Tendenz zur Homophonie ${ }^{90}$, die auch den entsprechenden Takten von $\mathrm{C} 1$ anzuhören war; ${ }^{91}$ sie markieren dort die diastematische Climax. In drei Schritten wandelt sich das Satzbild nun vom oszillierenden, dislozierten Cluster, der sich vom unmittelbaren Vorfeld nur marginal, allenfalls durch seine Dauer unterscheidet (T. 225-227.1) ${ }^{92}$, über einen bereits deutlich langsamer oszillierenden, terzengeschichteten Akkord, der mit seiner oberen Teilkomponente ins bislang nahezu vollständig ausgesparte viergestrichene Register hineinragt (T. 227.2-229.2, entsprechend $\mathrm{H}^{7}$ über C-Dur), hin zu einem stehenden Vierklang (wiederum nach Art eines dislozierten Clusters) als ausklingendem Rest desselben (T. 229.3-231).

Der Wechsel zwischen einem disloziertem Cluster und einem zwar komplexen, aber terzgeschichteten Schlussklang entspricht letztlich dem vertrauten Prinzip, dass auf eine >dissonante Penultima eine skonsonante Ultima folgt. Damit einher geht eine Änderung in der Klangqualität, die sich vor dem Hintergrund dieses Quartetts ausnimmt wie der

88 T. 209 f./129f.: -1/2; T. 211/131: -1/4; T. 212-222/132-142: untransponiert; 223 f./143 f. +1/2 bzw. $+1 / 4$.

89 Im Beispiel Anhang 3 sind bei den Takten 216-221 (der analogen Passage zu den Takten 136-141 und 171-176) die entsprechenden Zusätze klanglicher und dynamischer Art durch Umrahmungen gekennzeichnet; im satztechnischen Gerüst stimmt der Abschnitt weitgehend mit der Originalstelle überein.

90 D.h. im Kontext seines Komponierens zum simultanen Wechsel in die jeweils nächste oszillierende Klangfläche.

91 Vgl. Takt 142 ff.; spürbar ist die Tendenz zur Homophonie bereits ab etwa Takt 138.

92 Er entsteht durch eine Verbreiterung des beweglichen Strangs in Richtung des Liegetons (2. VI., Vla.), so dass der Abstand zwischen beiden Strängen (hier e und $b$ ) teils chromatisch, teils vierteltönig aufgefüllt wird. 
Übergang von einem `flüssigen` in einen `gasförmigen`Zustand. Hier scheint eine letzte Schwelle überschritten zu werden.

Deutlich wird dies zumal an der Ausführung der beiden letzten Stufen des Anstiegs: Erscheint der vorletzte Ton $b$ ausschließlich in der eingestrichenen Oktave, so verflüchtigt sich der letzte Ton $h$ ins dreigestrichene Register, ins Zentrum eines siebenstimmigen Akkordes, innerhalb dessen es schwerfällt, seine - im Sinne eines Teil-Fundaments ${ }^{93}$ theoretisch gegebene - Vorrangstellung herauszuhören.

\section{Résumé: Zyklizität und Drama}

Die Übertragung eines bestimmten Dramenmodells auf musikalische Formen im Verhältnis eins zu eins wird in den wenigsten Fällen vollständig gelingen. Musikalische Abläufe folgen in Vielem einer anderen 'Logikı, erzwingen andere Gliederungen, andere Gewichtungen, andere Höhepunkte, retardierende Momente und Schlüsse als theatralische Handlungen. Anders auch als im Theater manifestiert sich der Fortgang einer musikalischen `Handlung vielfach an der veränderten Wiederkehr des Gleichen, d. h. analoger Formkomponenten oder Abläufe: ${ }^{94}$ Das zu Beginn exponierte Material (im weitesten Sinne) und dessen Ablauf zeigen Tendenzen und Konflikte, nehmen Ziele vorweg, ohne sie auszuschöpfen. In der Wiederkehr wird am veränderten Klang, an der veränderten Farbe, Intensität oder Geschwindigkeit sowie an formalen Erweiterungen oder Ellipsen hörbar, dass die Tendenzen swirken`, dass die Konflikte wachsen, dass die musikalische Handlung in der Zeit ihre Spuren hinterlassen hat. Musikalisch gesehen ist Zyklizität daher eine Funktion der dramatischen Struktur, die «Konstante`, an deren Veränderung der dramatische Verlauf überhaupt erst erfahren wird, und Scelsi wäre nicht der erste und nicht der einzige Komponist, der auf diese Weise Form gestaltete.

Tabelle 8 versucht, zyklische und dramatische Struktur zu verbinden. Ausgangspunkt ist die Annahme, dass in musikalischen Formen die grundlegenden dramatischen Komponenten mehrfach und auf mehreren strukturellen Ebenen wiederkehren. ${ }^{95}$ So wird der insgesamt sehr zurückhaltende, langfristig aber auf den Beginn von $\mathrm{C}$ zustrebende Teil $B$ als Wechsel zwischen Vorantreiben und Retardieren beschrieben. In C1 bis C3 folgt auf die vorübergehende `Auflösung` (auch im musikalischen Sinn) jeweils der Anstieg (im Sinne des zu Beginn exponierten Grundimpulses) und dessen Umschlag (péripétie) in eine krisenhafte Zuspitzung (Verdickung zum Cluster und Abstieg), auf die wiederum

93 Als `Fundament der Teilkomponente $\mathrm{H}^{7}$.

94 Im Theater des 20. und 21. Jahrhunderts ist das zwar denkbar, aber eher die Ausnahme (etwa bei Beckett, Canetti, Bernhard).

95 Angelegt ist dies bereits in der französischen Dramentheorie des 17. und 18. Jahrhunderts, die - bei einer grundsätzlichen Dreiteilung in exposition, nœud und dénouement - die Möglichkeit mehrerer, strukturell unterschiedlich gewichteter Höhepunkte (péripéties) und damit implizit mehrerer, auch sprovisorischer`Auflösungen (dénouements) bietet (vgl. Scherer 1950, 84).

Rechte Seite: Tabelle 8: Scelsi, viertes Streichquartett, dramatische Lesart 


\begin{tabular}{|c|c|}
\hline $\begin{array}{l}\text { Exposition } \\
\text { (A, T. 1-46) }\end{array}$ & $\begin{array}{l}\text { Vorstellung und erste Entfaltung des `Tons` als eines komplexen, pulsierenden } \\
\text { und intern bewegten, von widerstreitenden Kräften gelenkten `Organismus`, als } \\
\text { sdramatis personas. Aus dem Antagonismus zwischen Anstieg und Beharren er- } \\
\text { gibt sich als syntaktische Grundfigur ein ständiger Wechsel zwischen Harmoni- } \\
\text { zität und Inharmonizität, Spannung und Lösung, Vorantreiben und Innehalten. } \\
\text { Bereitstellung wesentlicher satztechnischer und formaler Komponenten; am } \\
\text { Ende Andeutung erster akkordähnlicher Komponenten. }\end{array}$ \\
\hline $\begin{array}{l}\text { Steigerung I } \\
\text { (B1, T. } 46-74 \\
\text { und B2, } \\
\text { T. } 74-112)\end{array}$ & $\begin{array}{l}\text { Erste, sehr zurückhaltende, zum vorläufigen Höhepunkt führende Steigerung als } \\
\text { Wechsel zwischen Vorantreiben und Retardieren } \\
\text { B1 } \\
\text { T. 48: Neuansatz durch lagenmäßige Verengung } \\
\text { T. 50: Einführung eines im buchstäblichen Sinne serregenden` Moments durch } \\
\text { Beginn einer durchgängigen Oszillation sowie der für die weitere Entwicklung } \\
\text { prägenden Konstellation aus liegendem und oszillierendem Strang } \\
\text { T. 63: retardierendes Moment I durch Störton } d^{1} \text {, Aussetzen der Oszillation, di- } \\
\text { astematische Verengung und gleichzeitige registermäßige Öffnung in Richtung } \\
\text { eines zäsursetzenden Unisono-d (T. 74) } \\
\text { B2 } \\
\text { T. 74-80: Wiederherstellung der Konstellation aus T. 50; Gegenüberstellungen } \\
\text { von Harmonizität und Inharmonizität (T. 80/82 vs. T. 83; T. 86 vs. T. 90), dabei } \\
\text { erste Andeutung einer Großterzrelation (T. 80/82) } \\
\text { T. 90: retardierendes Moment II durch Störton } d^{1} \text { (T. 90), Aussetzen der Oszil- } \\
\text { lation, Anhebung (bis T. 95), weitere Großterzrelationen (T. 94/97) und dyna- } \\
\text { mischen Tiefpunkt (T. 98f.). } \\
\text { T. 99: Störton } d^{2}, \text { zerdehnte Anhebung (ab T. 101, spannungssteigernd) und >Do- } \\
\text { minantorgelpunkt` (T. 106-112) }\end{array}$ \\
\hline $\begin{array}{l}\text { Steigerung II } \\
\text { (C1, T. 113-157) }\end{array}$ & $\begin{array}{l}\text { Zweite, zum eigentlichen Höhepunkt führende Steigerung } \\
\text { T. 113-119: Auflösung und Plateau als vorläufiger Höhepunkt einhergehend mit } \\
\text { ‘A-Dur-Dreiklang und Eintritt des Liegetons cis (T. 113-134) } \\
\text { T. 120: Beginn einer zunächst vorwiegend linearen Steigerung, dabei angedeu- } \\
\text { tete Großterzrelation zu A in T. 123f. bzw. T. } 129 \\
\text { T. 135: Intensivierung durch definitiven Eintritt des dreigestrichenen Registers } \\
\text { und Loslösung vom Liegeton } \\
\text { T. 141: Peripetie I mit diastematischem Hoch- und Wendepunkt; zugleich Be- } \\
\text { ginn einer krisenhaften Zuspitzung durch fortschreitende Intensivierung (Triller, } \\
\text { Tremoli) und klangliche Verzerrung bis zum Cluster }\end{array}$ \\
\hline $\begin{array}{l}\text { Höhepunkt und } \\
\text { Umkehr } \\
\text { (C2, } \\
\text { T. 158-195) }\end{array}$ & $\begin{array}{l}\text { T. 158: Auflösung und Plateau als eigentlicher und saffirmativer } \text { Höhepunkt } \\
\text { unter weitgehendem Verzicht auf oszillierende Elemente und Ausfilterung von } \\
d \text { und f; } d \text { als Liegeton bzw. Orgelpunkt (bis T. 209); >dorisches Tetrachord } \\
d \text {-e-f-g (T. 163-177), B-Dur-Dreiklang (T. 167), ,Chorals-Fragment im Violon- } \\
\text { cello (T. 172-177) } \\
\text { T. 169: beginnende Analogie zu C1 (T. } 135 \text { ff.), d. h. Intensivierung durch Hinzu- } \\
\text { schaltung des dreigestrichenen Registers; kaum weiterer Anstieg } \\
\text { T. 178: Peripetie II, d. h. beginnende Verzerrung, kaum Richtungsänderung, vor } \\
\text { allem Cluster und tremolo sul ponticello }\end{array}$ \\
\hline $\begin{array}{l}\text { Katastrophe } \\
\text { und Katharsis } \\
\text { (C3, } \\
\text { T. 196-231) }\end{array}$ & $\begin{array}{l}\text { T. 196: Auflösung und Plateau als ınegativer Höhepunkt bzw. Katastrophe } \\
\text { T. 208/10: Loslassen (vom Orgelpunkt) und erneuter Anstieg (auch des sliegen- } \\
\text { den` Strangs); beginnende Analogie zu C1 (T. 209-224 entsprechend T. 129-144) } \\
\text { T. 225-31: Katharsis }\end{array}$ \\
\hline
\end{tabular}


eine neue `Auflösung، folgt, oder - indem schließlich Anstieg und Zuspitzung zusammenfallen - die Katharsis. Geht man vom Modell der $>$ dramatischen Pyramide ${ }^{96}$ aus, so erscheint jede der drei >Auflösungen ‘ an einer anderen Position: Die Takte $113 \mathrm{ff}$. sind Teil der steigenden Kurve, die Takte $158 \mathrm{ff}$. bilden den Scheitelpunkt und die Takte $196 \mathrm{ff}$. erfolgen bereits inmitten der fallenden Kurve. In diesem übergreifenden Sinne markiert C1 als Ganzes den Beginn des zentralen Konflikts, C2 dessen Fortführung bis zur eigentlichen (letzten) Peripetie und C3 die Katastrophe. B1 wäre demnach ambivalent zwischen fortgesetzter Exposition (Einführung der für die Handlung wesentlichen Antagonismen) und zögerndem Beginn der Steigerung.

Betrachtet man die Durdreiklänge bzw. die tonalen Allusionen zu Beginn der Abschnitte C1-3 als zwar immer noch ıberührende`, aus `Sicht dieses Quartetts` aber historisch überlebte bzw. heruntergekommene Chiffren des Reinen, Vollkommenen, so entspräche die abschließende Verflüchtigung in den Bereich des kaum noch Hörbaren, als ein Hinausweisen in einen Bereich jenseits der Hörschwelle, einer Überschreitung, für die der Begriff Katharsis durchaus angemessen wäre.

\section{Postscriptum: Nochmals zu Schaffensprozess und Autorschaft}

Die Zweit- und Drittverwertung ganzer Stimmauszüge innerhalb späterer Formteile scheint - als Montageverfahren - zunächst die Aussagen von Scelsis Assistenten zu bestätigen, wonach das ihnen vorgelegte Material in erster Linie aus Tonbändern bestand und Scelsi auch mit Playback-Verfahren arbeitete. ${ }^{97}$ Wenn dem so ist, dann setzt die genaue Transkription der so zustande gekommenen Aufzeichnungen eine sehr enge Kooperation zwischen Komponist und Transkriptor voraus - sei es, dass Scelsi über den Herstellungs-Prozess seiner Bänder exakt Buch geführt hat (eher unwahrscheinlich), oder dass er für diese Passagen anstelle einer bis ins Detail ausgearbeiteten und vverbindlichen< Bandvorlage lediglich einen Plan zur Ausarbeitung vorlegte ${ }^{98}$, dessen Realisierung er anschließend (d.h. im vorliegenden Falle auch noch während der Proben zur Ersteinspielung ${ }^{99}$ ) im Einzelnen mit dem Transkriptor durchging. ${ }^{100}$ So hätte für die Takte 209-224 (C3) eine Skizzierung des Stufengangs genügt; für die Takte 170-192 (C2) wäre über die oben formulierten Direktiven hinaus (Ausdünnung der beiden tiefen Register, der Ton $G$ und seine beiden mikrotonalen Nachbarn als oberer Grenzton) eine

96 Freytag 2003, 95.

97 Jäcker 2005, 31, sowie 39, Anm. 43 und Uitti 1995, 11.

98 Mit genauen Angaben darüber, welche Passage wo und mit welchen Modifikationen übernommen werden sollte.

99 Vgl. Sciannameo 2001, 24: „Tosatti conducted and took notes of any eventual adjustments made to the score $[\ldots]$ «.

100 Gesetzt den Fall, dass Scelsis technische Ausstattung in den 60er Jahren es den Transkriptoren ermöglichte, die einzelnen Kanäle getrennt abzuhören, bleibt es unwahrscheinlich, dass sie einen Stimmausschnitt, der sich - so ist zumindest anzunehmen - weder rhythmisch noch diastematisch exakt in das bestehende Notationssystem einpassen ließ, dreimal in exakt derselben Weise interpretierten, ohne zumindest den Hinweis zu haben, dass es sich bei den Takten 170-179 und 215-224 um den gleichen Stimmausschnitt wie in Takt 135-144 handelt. Vgl. auch Jäcker 2004, 71. 
(Band-)Vorlage der >dorischen Fragmente hinreichend gewesen. Auch die eher ernüchternde Vorstellung, das Montageprinzip verdanke sich arbeitsökonomischen Überlegungen Tosattis, ist nicht gänzlich auszuschließen. Ob die erhaltenen Quellen - und das wären über die Tonbänder hinaus auch verbale Skizzen, ggf. auch Noten - eine Klärung dieser Fragen erlauben, bleibt abzuwarten.

\section{Literatur}

Anderson, Christine (1998), Giacinto Scelsi: Anahit. Ästhetischer Hintergrund und Analyse, Berlin (Magisterarbeit, TU Berlin).

Anderson, Christine (1999a), „Klang als Energie. `Anahit` von Giacinto Scelsi - ästhetischer Hintergrund und Analyse«, in: MusikTexte. Zeitschrift für neue Musik 81/82, 72-83.

— (1999b), „Verhaltensnormen, Regeln und Räume«, MusikTexte. Zeitschrift für Neue Musik, 81/82, 1999, 42-47.

Angermann, Klaus (Hg.) (1993), Giacinto Scelsi: Im Innern des Tons. Symposion , Giacinto Scelsi Hamburg 1992, Hofheim: Wolke.

Asmuth, Bernhard (1990), Einführung in die Dramenanalyse, Stuttgart: Metzler.

Bandur, Markus (2007), „Giacinto Scelsi«, in: Komponisten der Gegenwart (KdG), 24. Lfg. 2007, 44 Seiten.

Filippini, Riccardo (2005) »Scelsis ıStück mit den Gläsern« (kommentiert von Friedrich Jaecker), MusikTexte. Zeitschrift für Neue Musik, 105, 19-20.

Freytag, Gustav (2003), Die Technik des Dramas, (Ausgabe nach Freytag, Gustav: Gesammelte Werke, Ser. 1, Bd. 2, Leipzig: Hirzel 1915, bearbeitet von Manfred Plinke), Berlin: Autorenhaus.

Halbreich, Harry (1990), »Les 5 quatuors à cordes, trio à cordes, khoom«, Booklet zur CD Giacinto Scelsi, 5 string quartets, string trio, khoom, Arditti String Quartet 1990, SCD 8904-5, 13-21.

Jaecker, Friedrich (2004), »Explodierende Asteroiden, Giacinto Scelsi: `Aitsiく und `Quartetto $n^{\circ}$ 5«", MusikTexte. Zeitschrift für Neue Musik 100, 65-73. (2005), »)Der Dilettant und die Profis« - Giacinto Scelsi, Vieri Tosatti \& Co.«, in: MusikTexte. Zeitschrift für Neue Musik 104, 27-40.

Koch, Hans W. (1999), »Musik unter der Lupe. Gacinto Scelsis Komposition `Pranam Ik von 1973«, MusikTexte. Zeitschrift für neue Musik 81/82, 83-92.

Menke, Johannes (2004), Pax. Analyse bei Giacinto Scelsi: 'Tre Canti sacri und 'KonxOm-Paxı (= Sinefonia 1), Hofheim: Wolke.

Murail, Tristan (1999), "Scelsi, De-compositore», in: Giacinto Scelsi. Vaggio al centro des suono, hg. von Pierre Albert und Castanet und Nicola Cisternino, La Spezia: LunaEditore 1992, zitiert nach: „Wegbereiter des Spektralen. Scelsi, der De-Komponist", aus dem Franz. übers. von Martin Kaltenecker, MusikTexte. Zeitschrift für neue Musik 81/82, 59-63, 
(2005), „Scelsi, I'Itinéraire - I'exploration du son«, Le Journal de Royaumont 2 (1988), zitiert nach: „Scelsi and L'Itineraire: The exploration of sound", Contemporary music review 24/2-3: Models \& artifice - The collected writings of Tristan Murail, hg. von Joshua Fineberg und Pierre Michel, 181-185.

Scherer, Jacques (1950), La dramaturgie classique en France, Paris: Librairie Nizet.

Schroeder, Marianne (1988), „Nach oben«, MusikTexte. Zeitschrift für neue Musik 26, 27-28.

Sciannameo, Franco (2001), »A personal memoir. Remembering Scelsi«, The Musical Times 142, 22-26.

Uitti, Frances-Marie (1995), »Meister der Improvisation. Zum Stand der Scelsi-Forschung", MusikTexte. Zeitschrift für neue Musik 60, 10-12.

Zenck, Martin (1983), „Das Irreduktible als Kriterium der Avantgarde. Überlegungen zu den vier Streichquartetten Giacinto Scelsis«, in: Giacinto Scelsi (= Musik-Konzepte 31), hg. von Heinz-Klaus Metzger und Rainer Riehn, München: edition text + kritik, 67-81.

\section{Anhang 1: Scelsi, viertes Streichquartett, Reduktion}
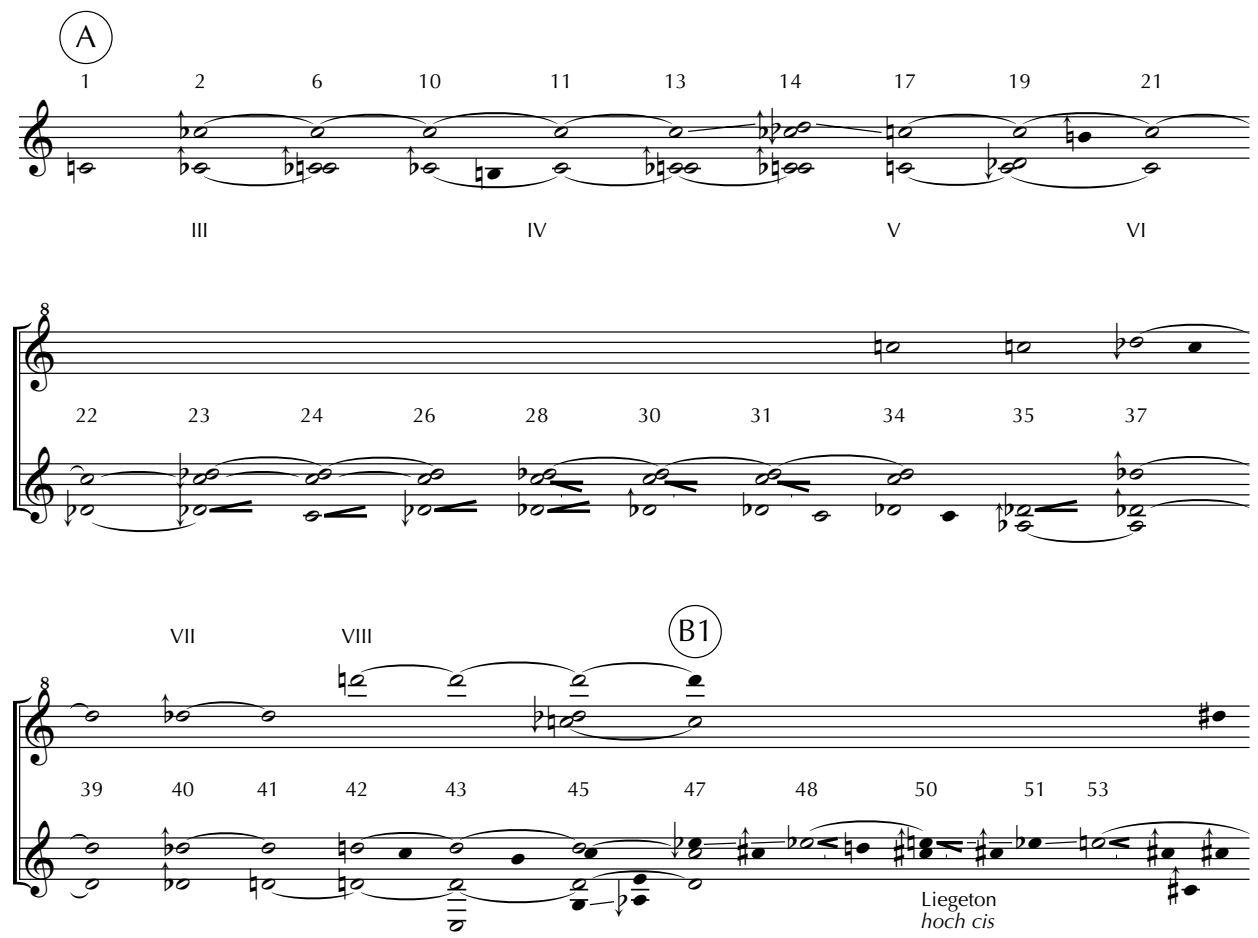


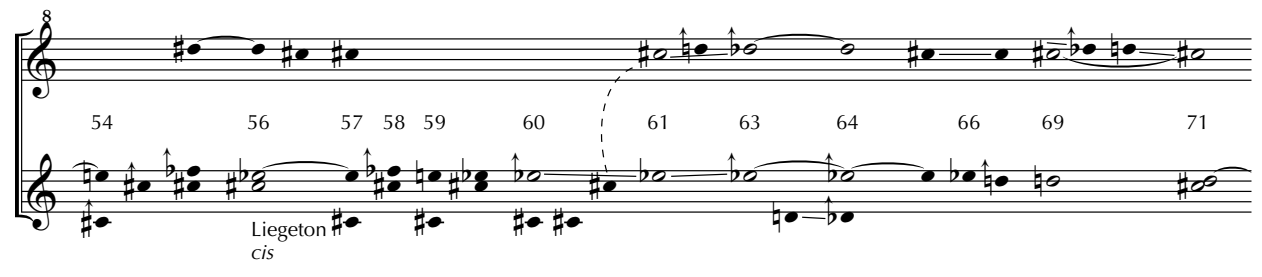

(B2)
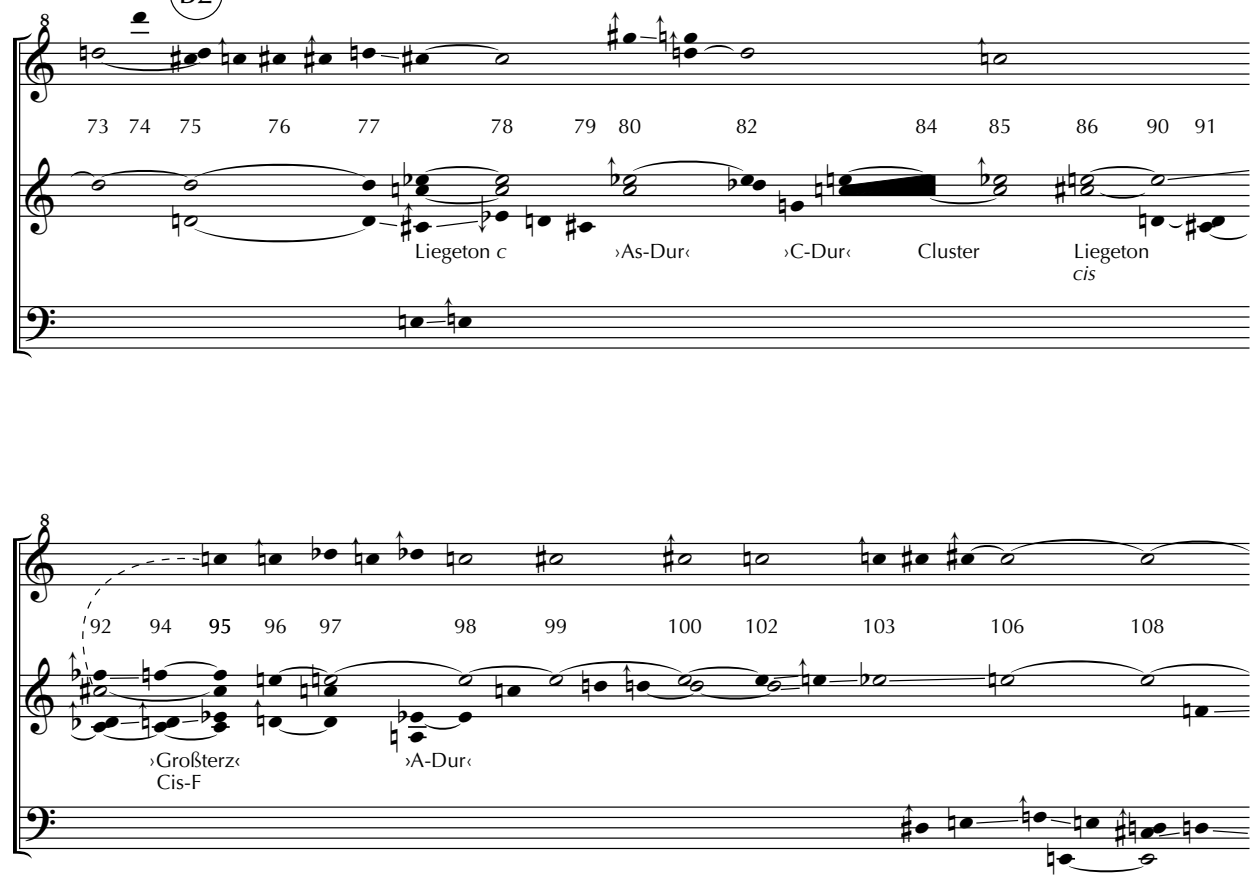

(C1)

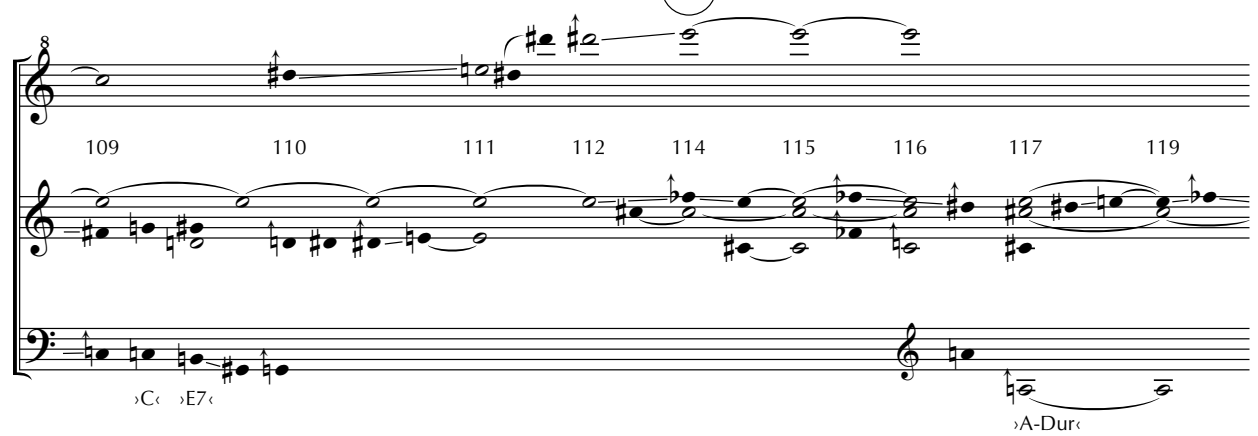



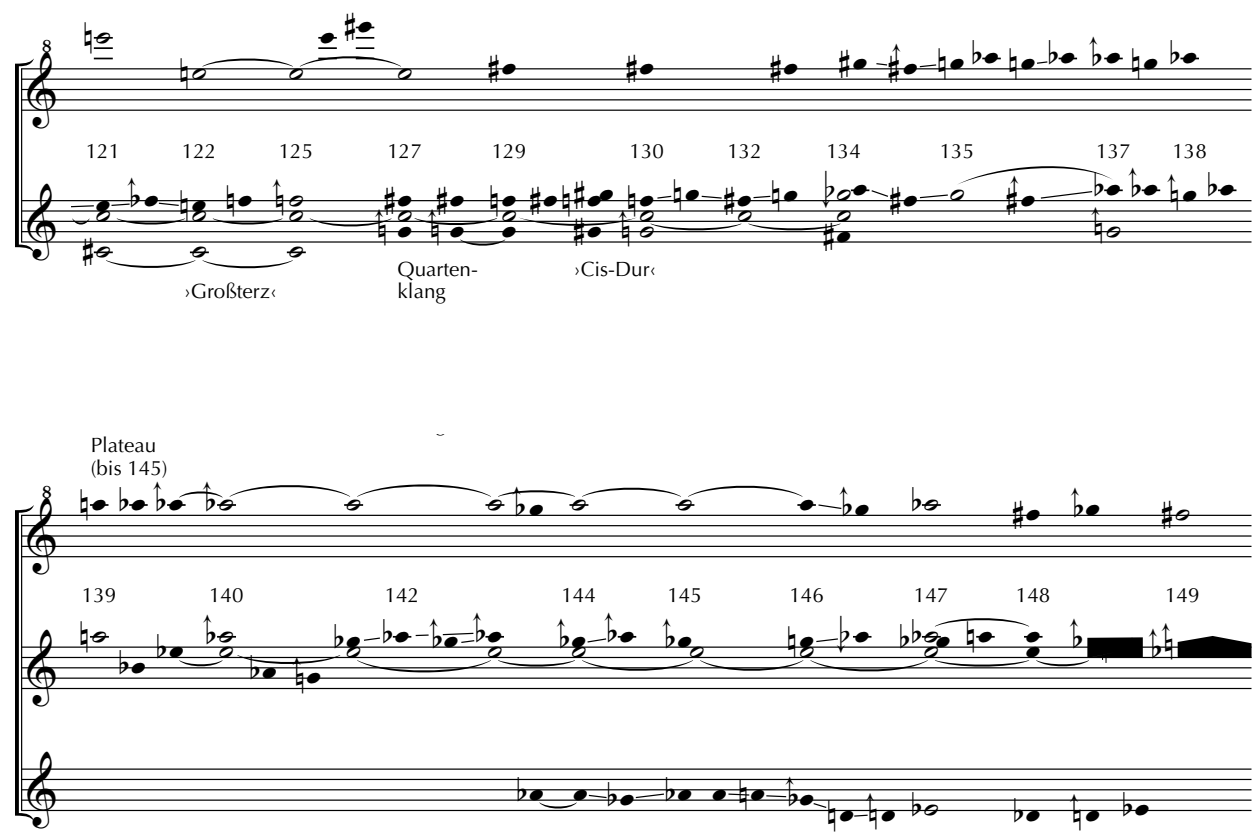

(C2)
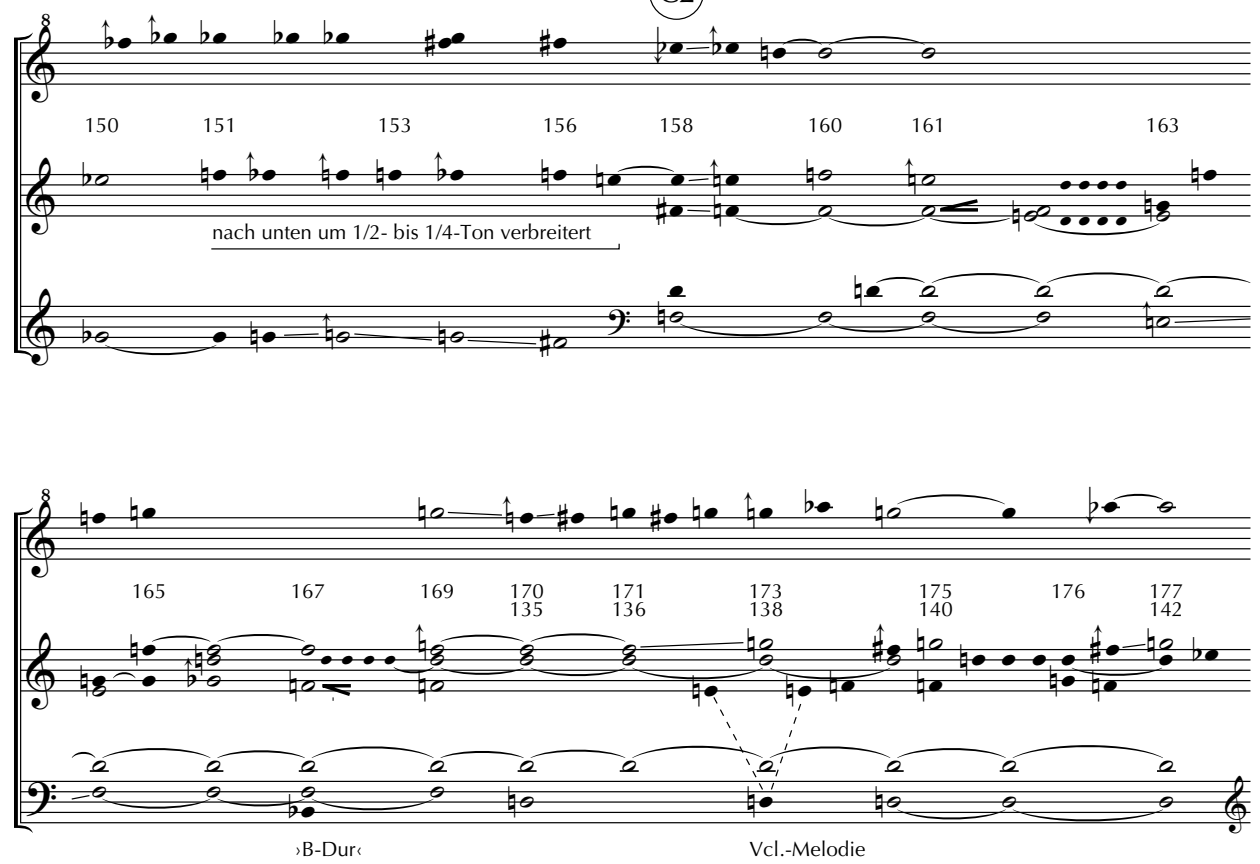


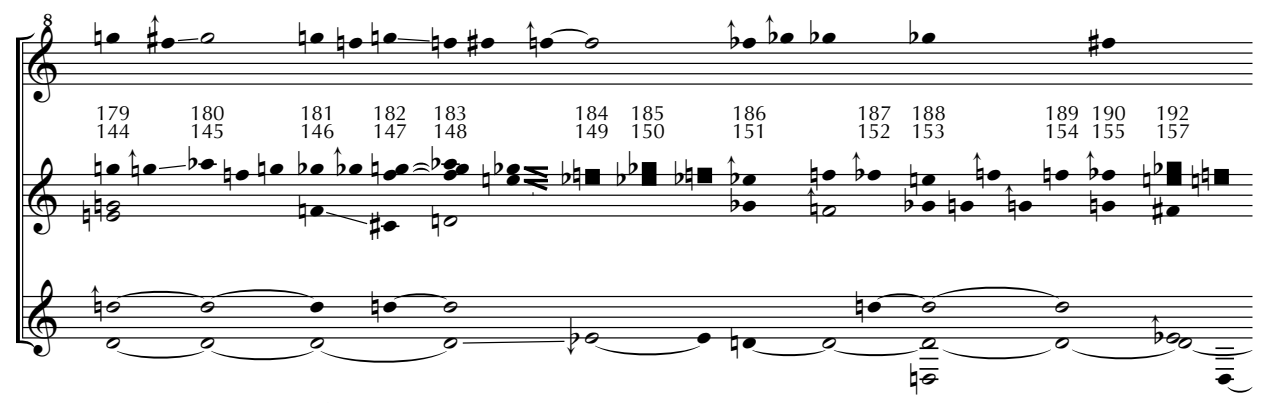

(C3)
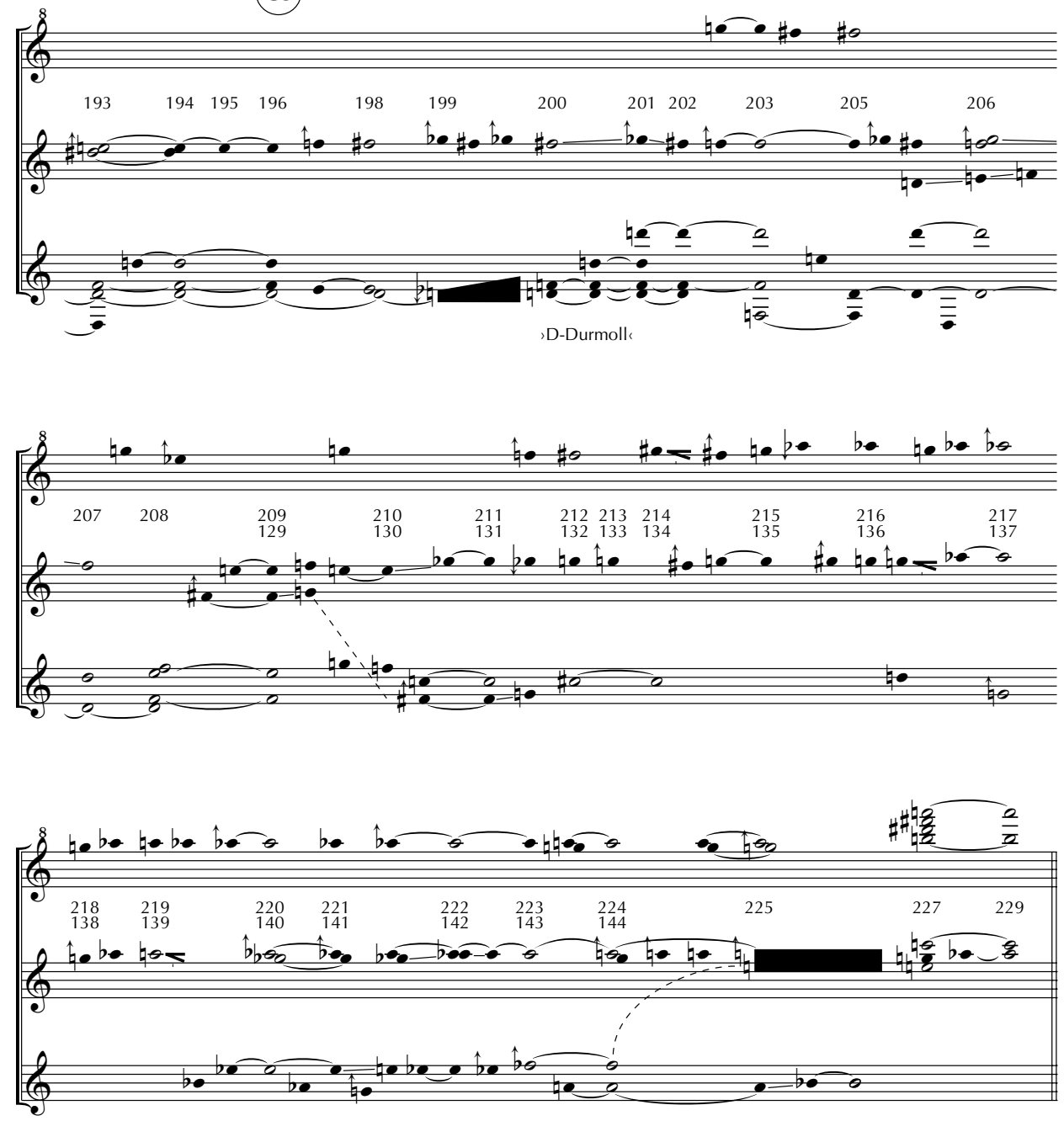
Anhang 2: Scelsi, viertes Streichquartett, Takte 89-119

89

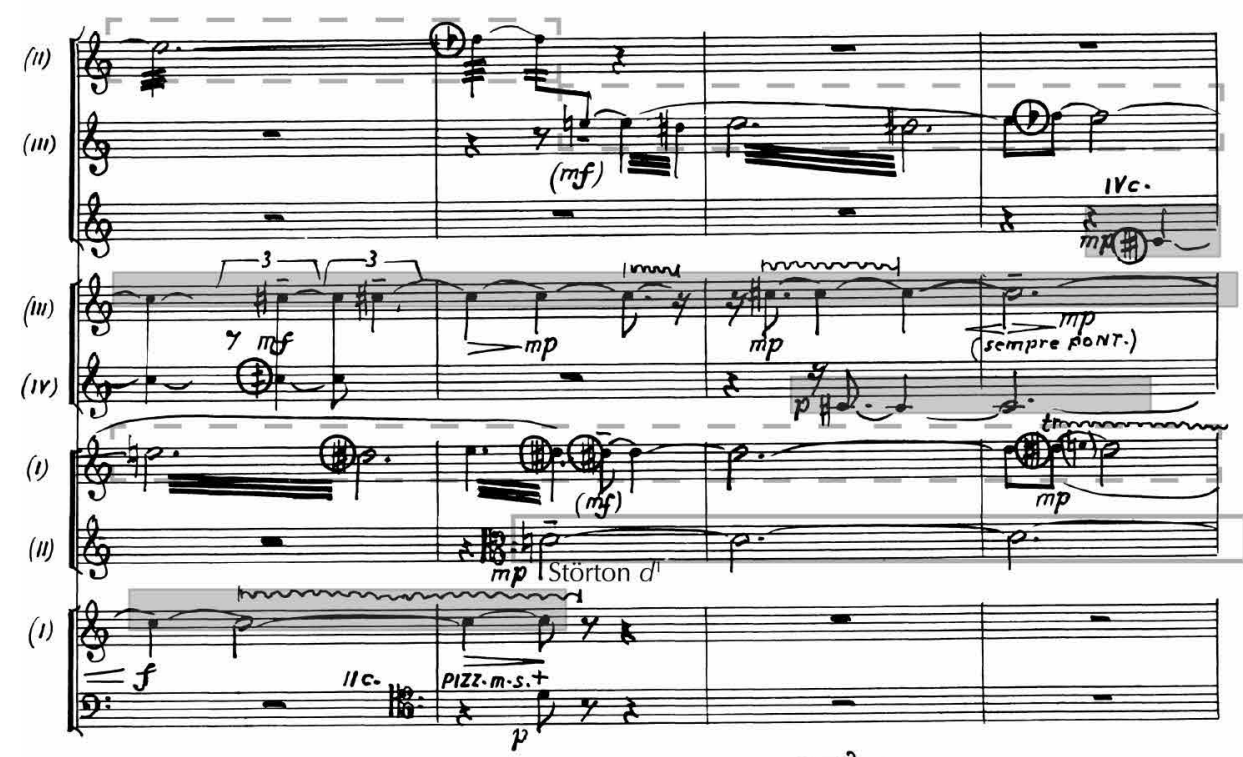

92

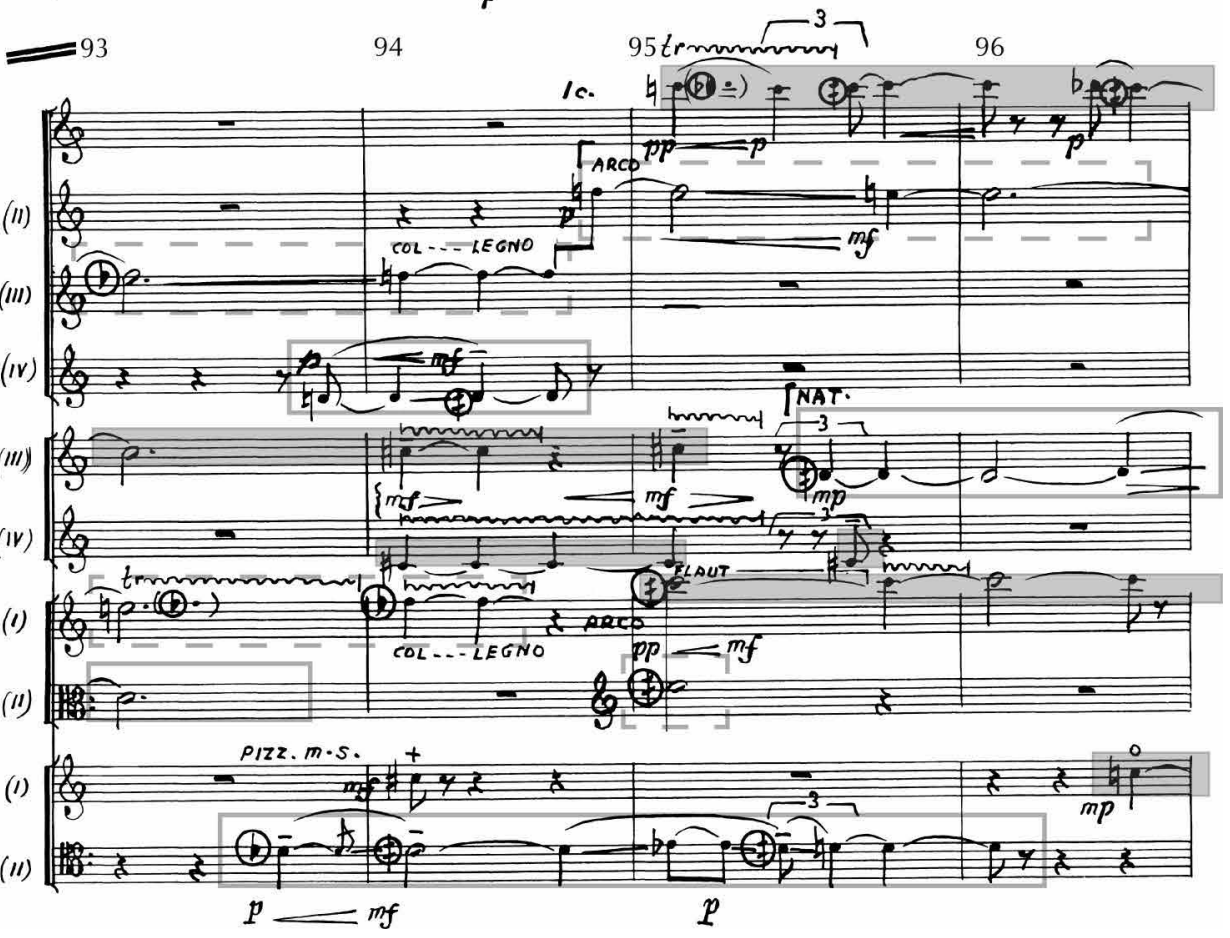




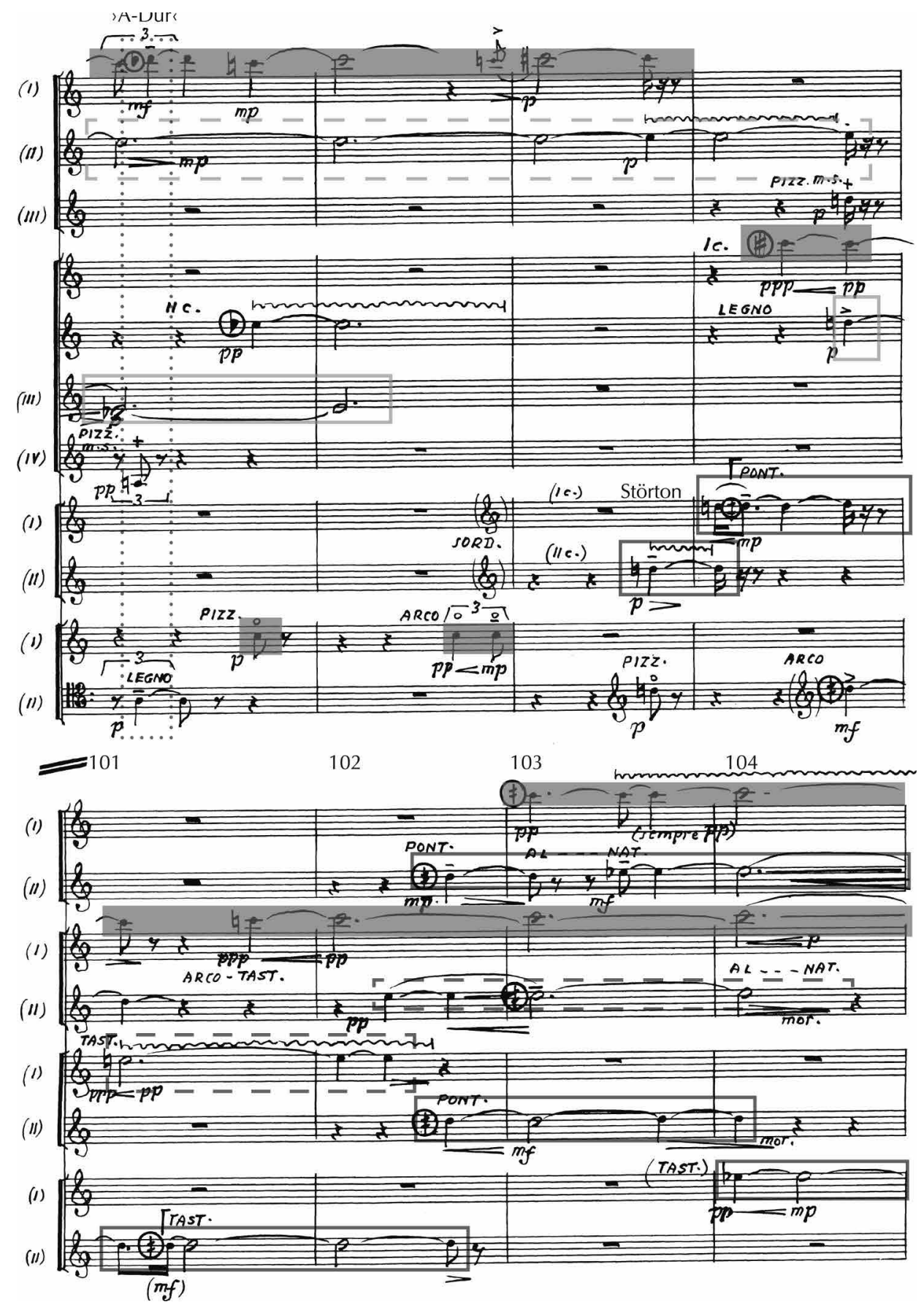




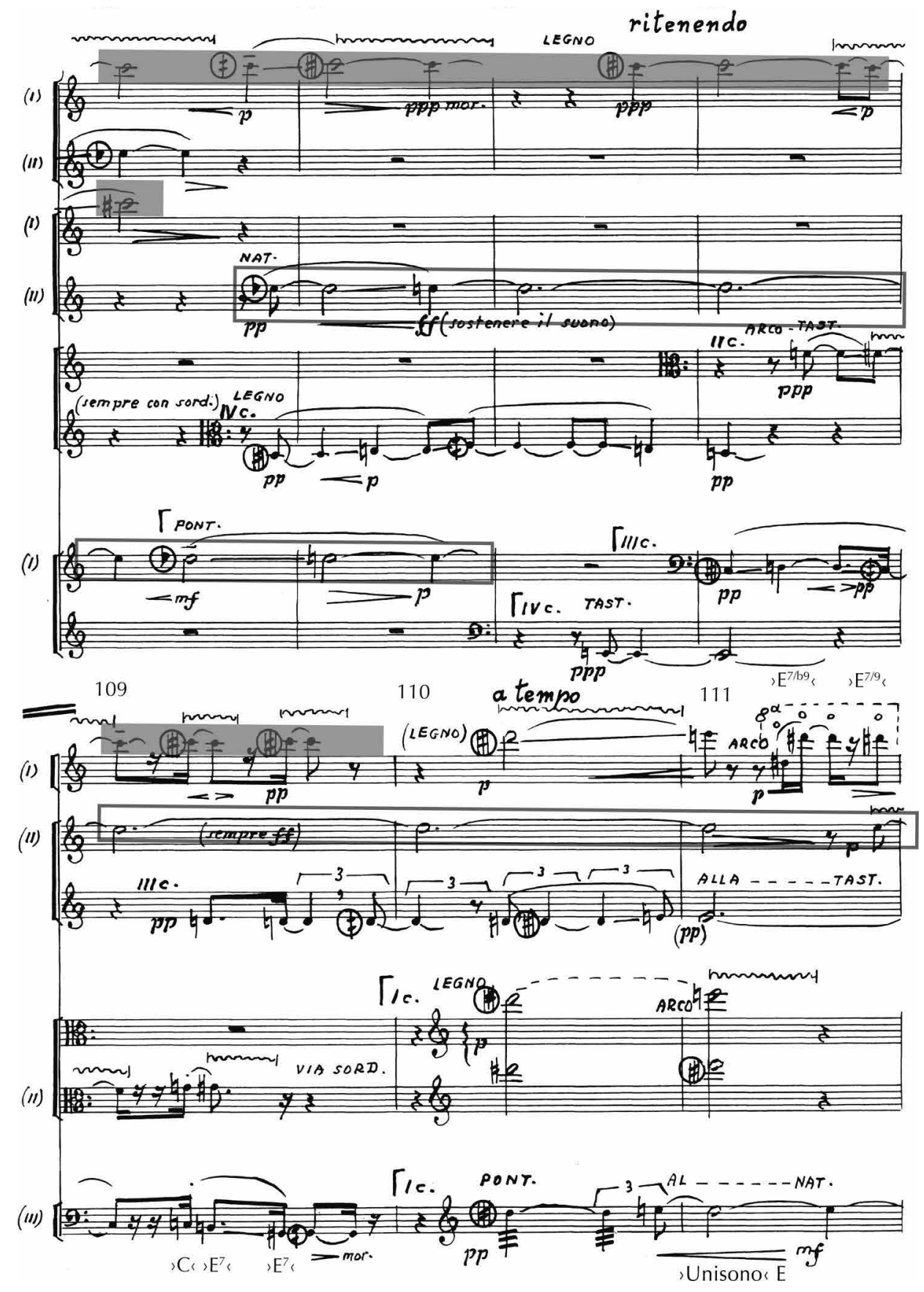



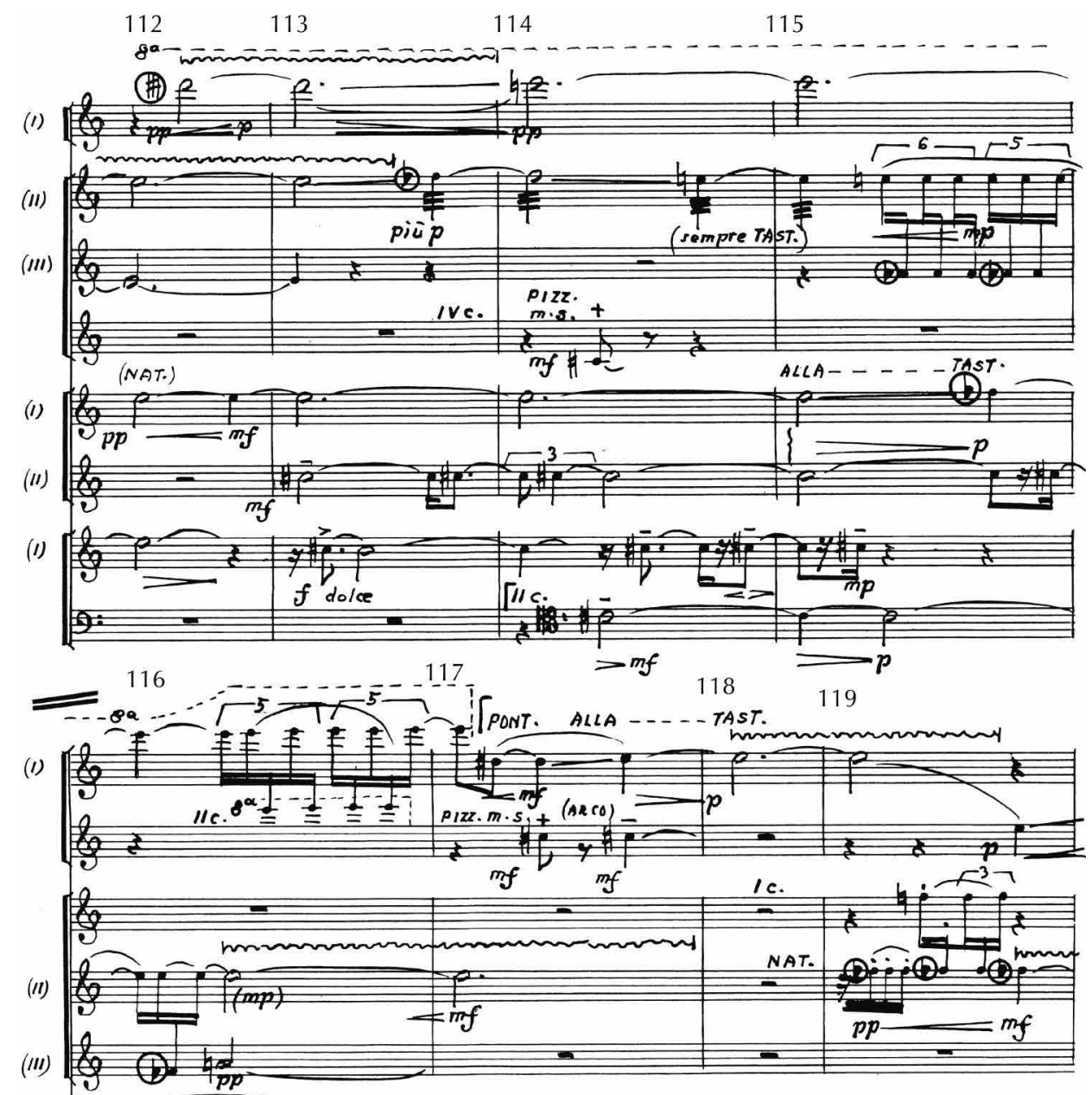

(III)

(I)

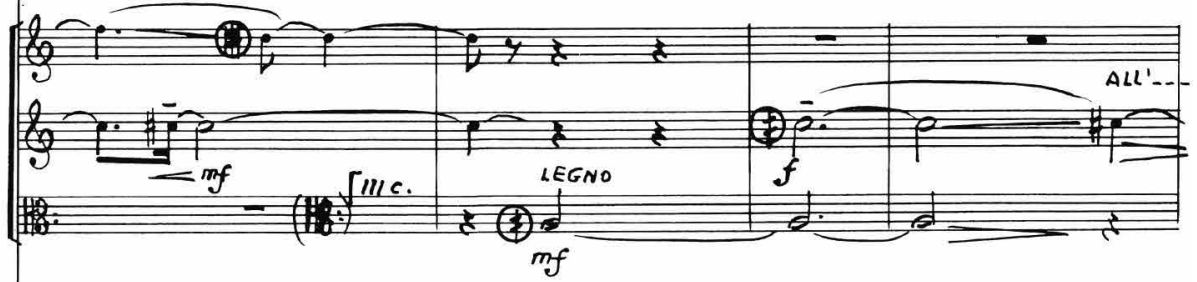

(iI) 
Anhang 3a: Scelsi, viertes Streichquartett, Takte 134-45

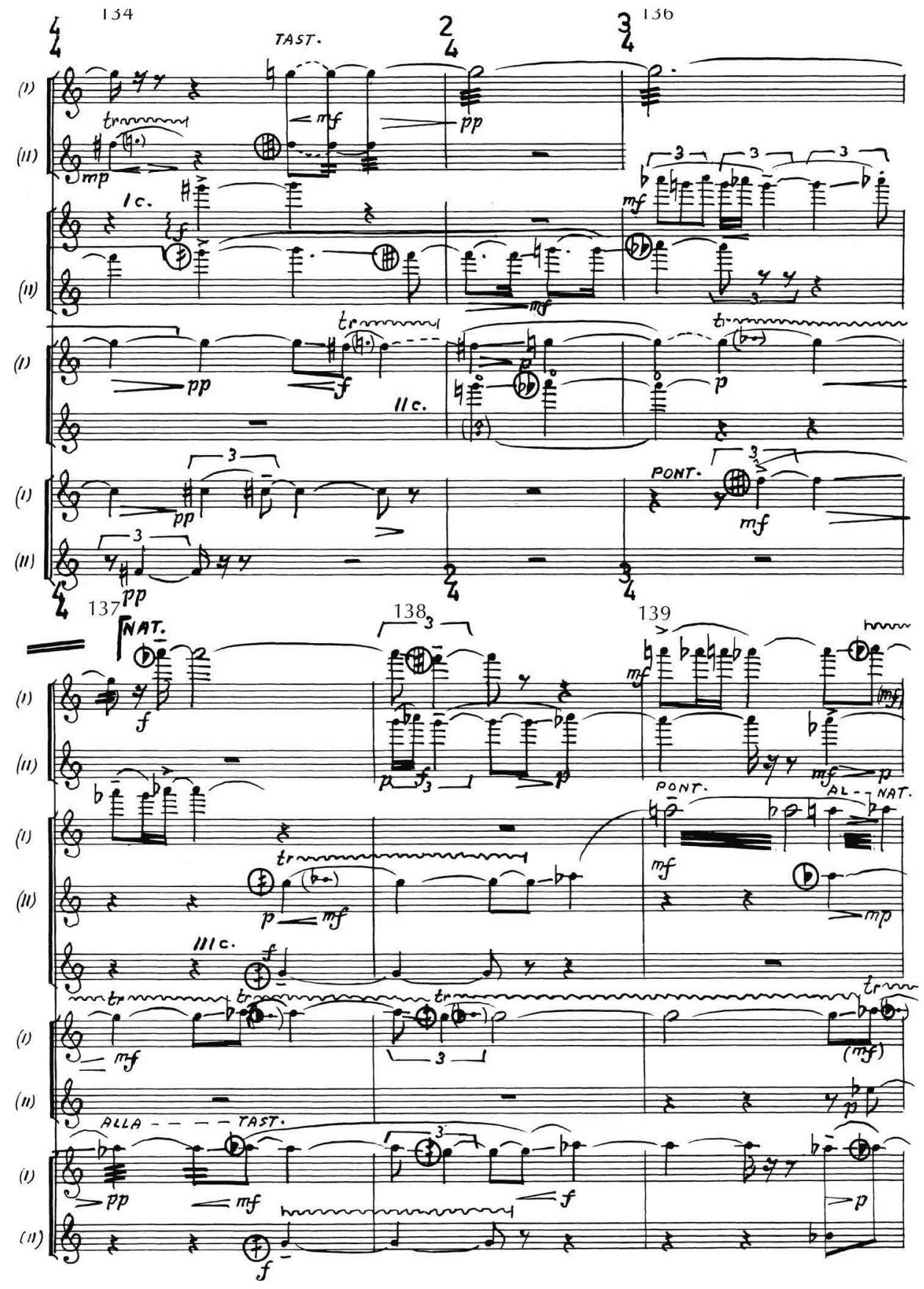



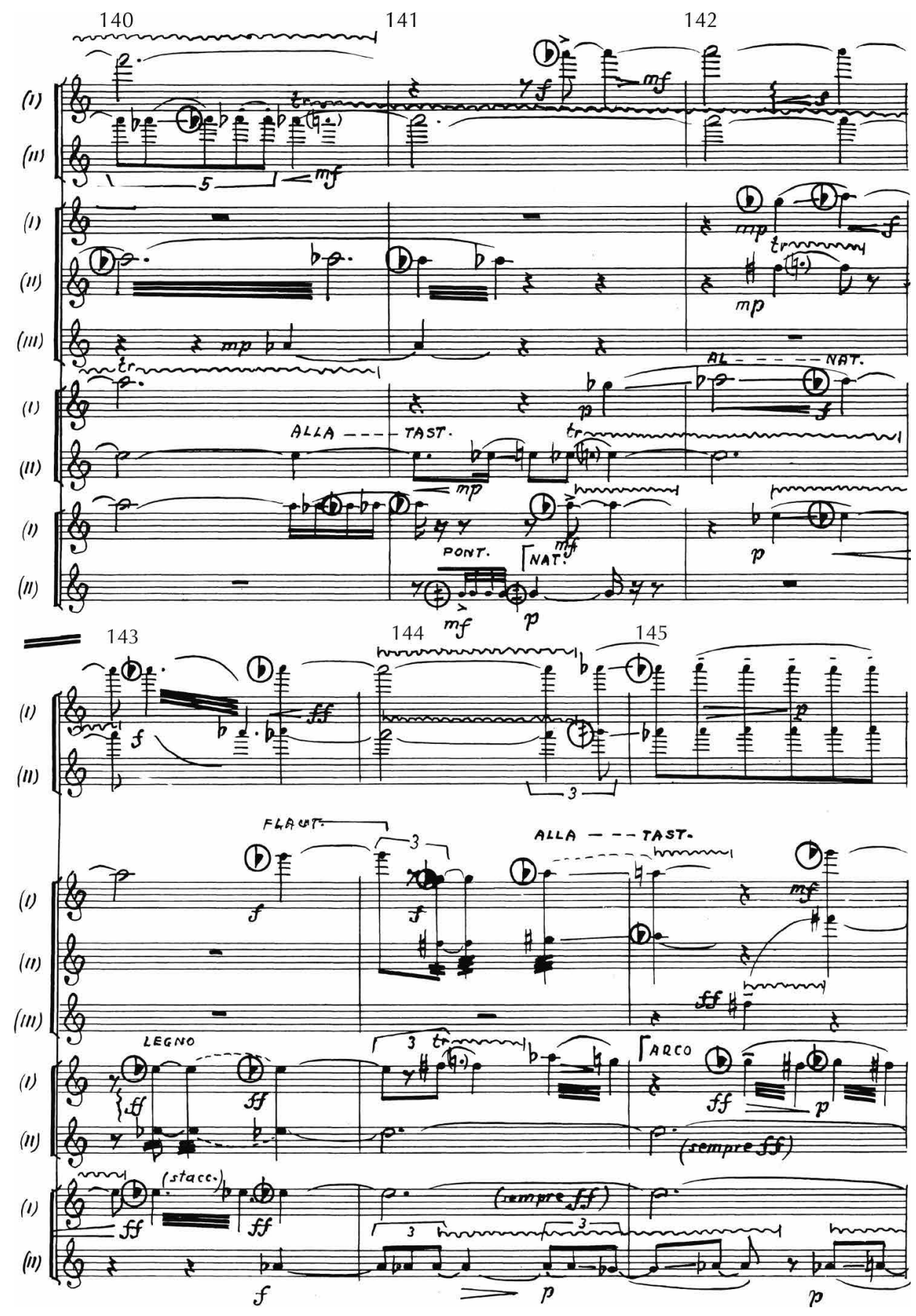
Anhang 3b: Scelsi, viertes Streichquartett, Takte 171-76 (resp. Takte 136-41

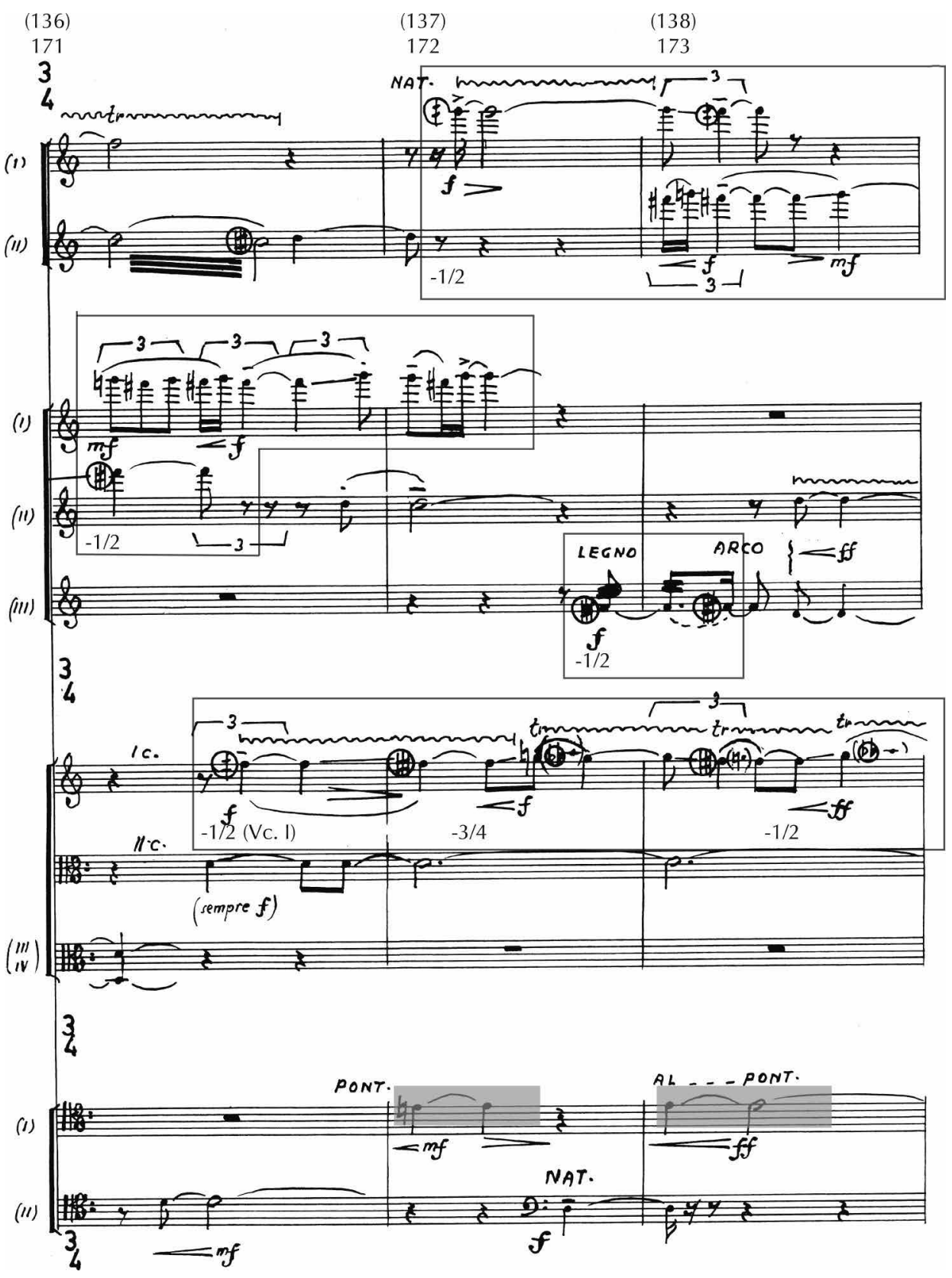




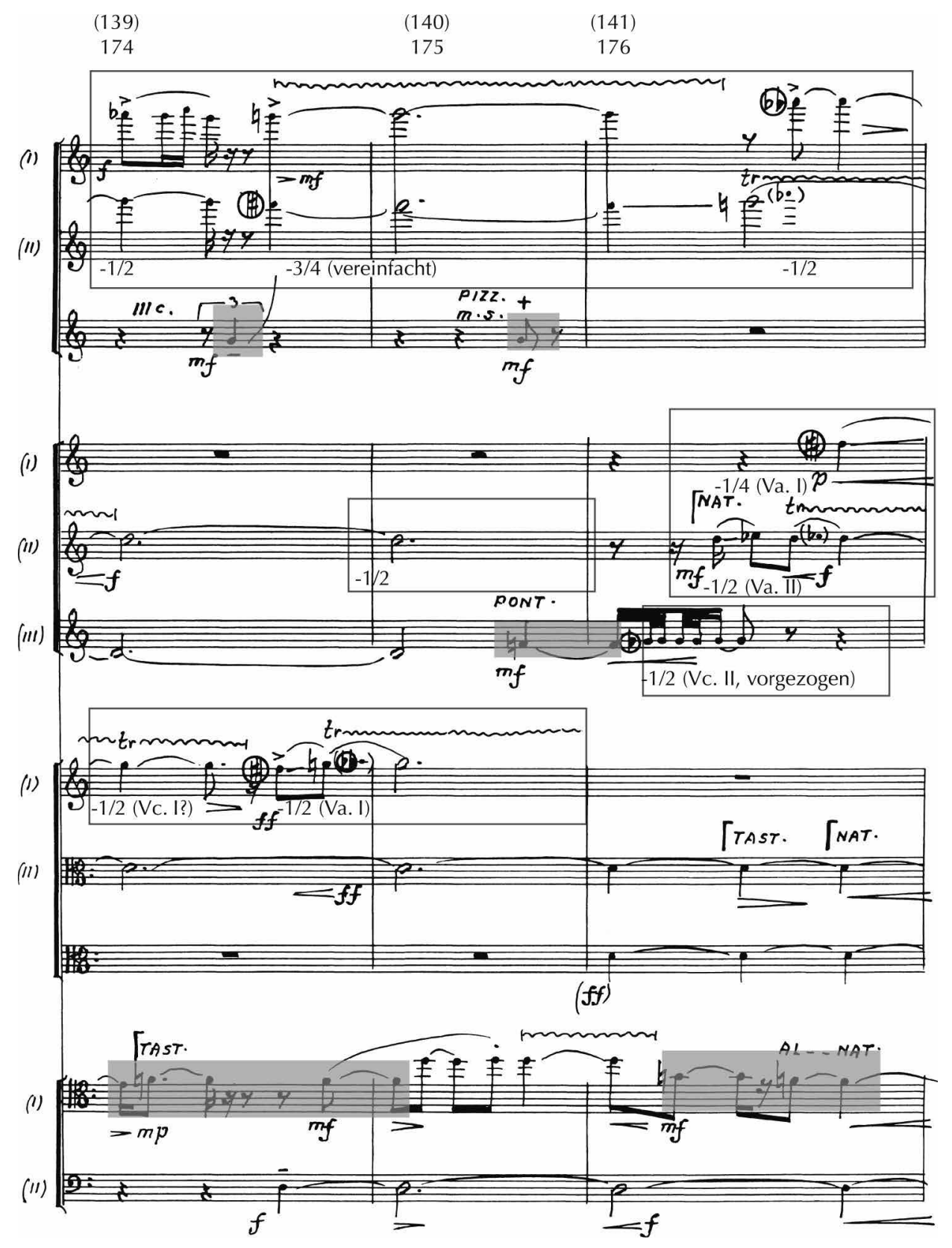


Anhang 3c: Scelsi, viertes Streichquartett, Takte 216-21

(resp. Takte 136-41)

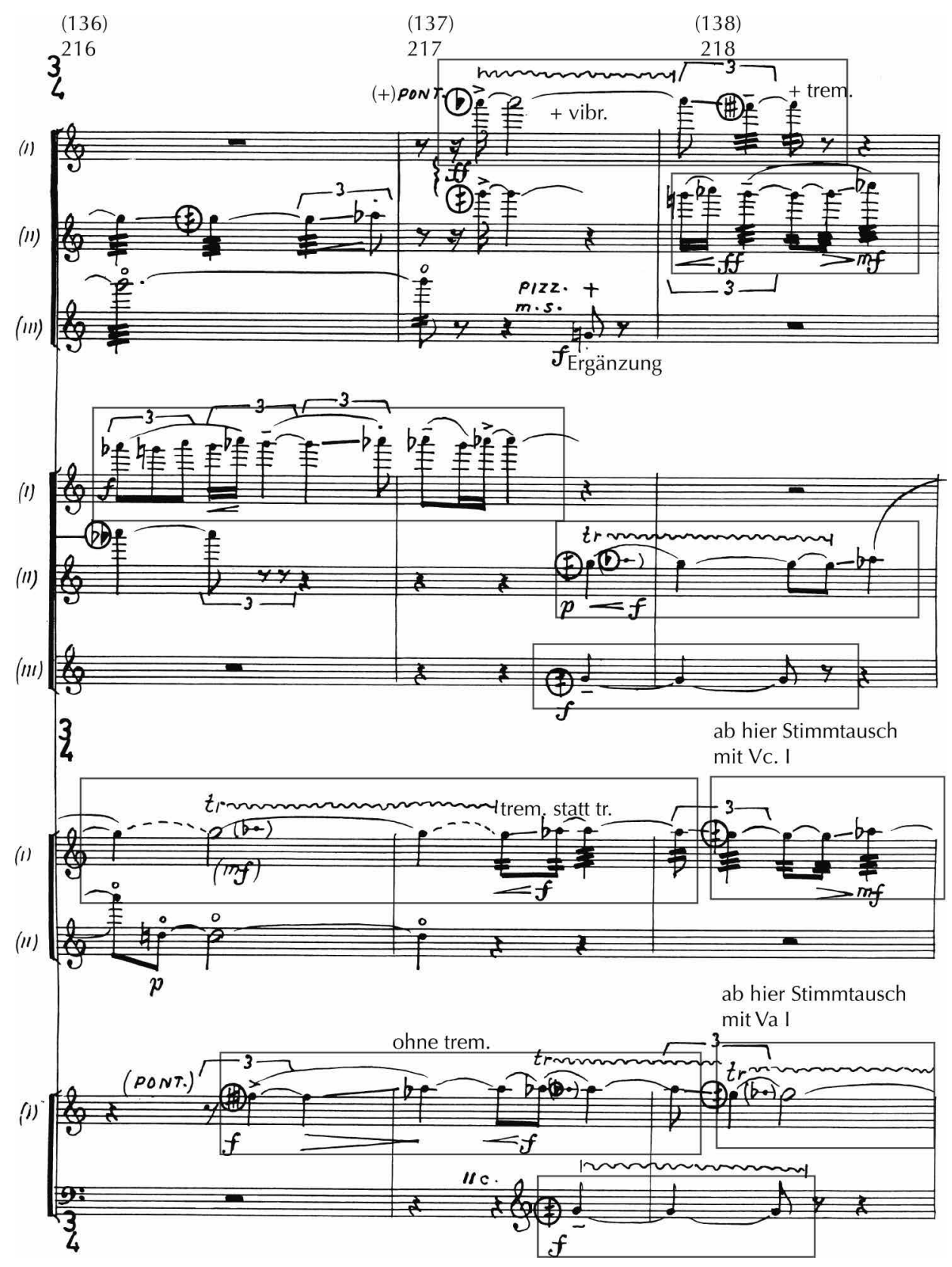


(139)

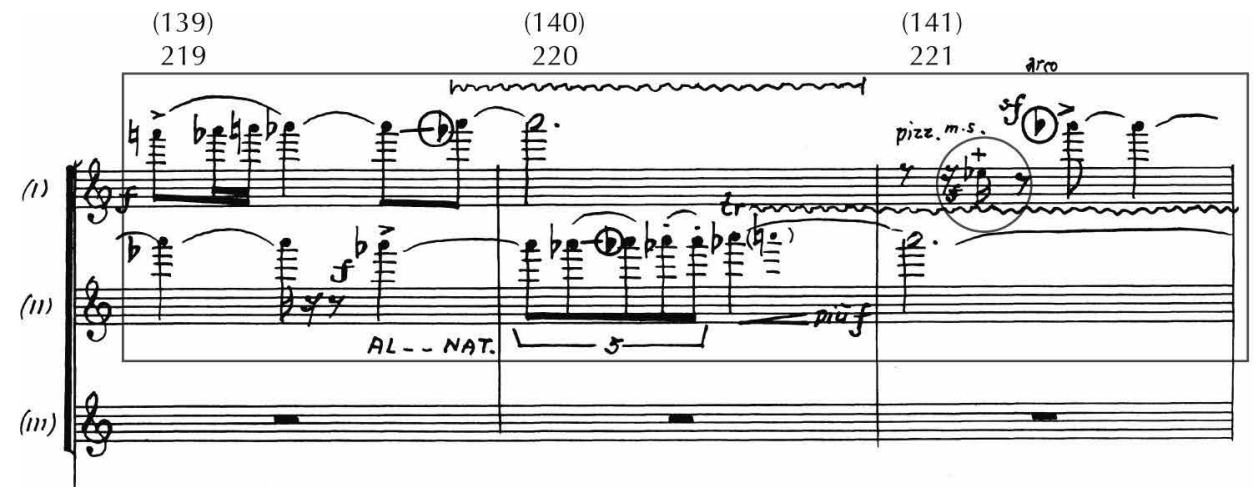

(1)

(II)

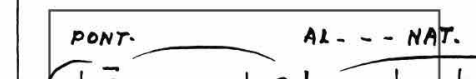

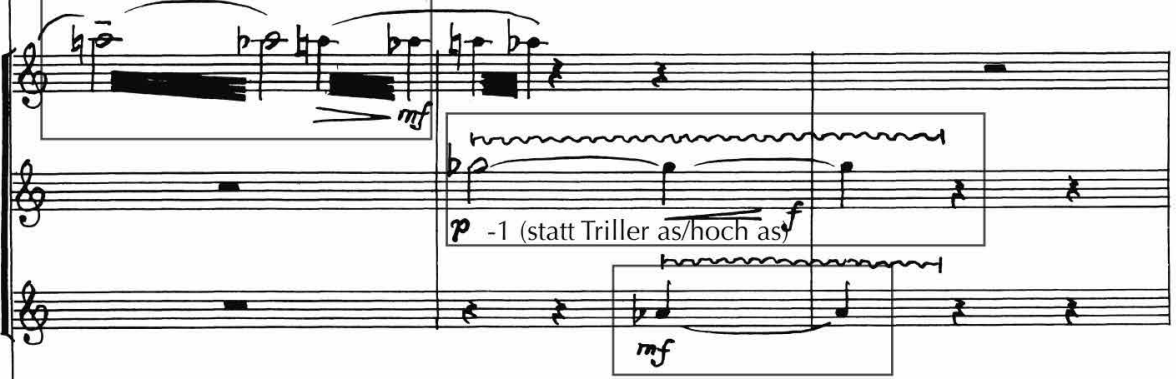

(III)
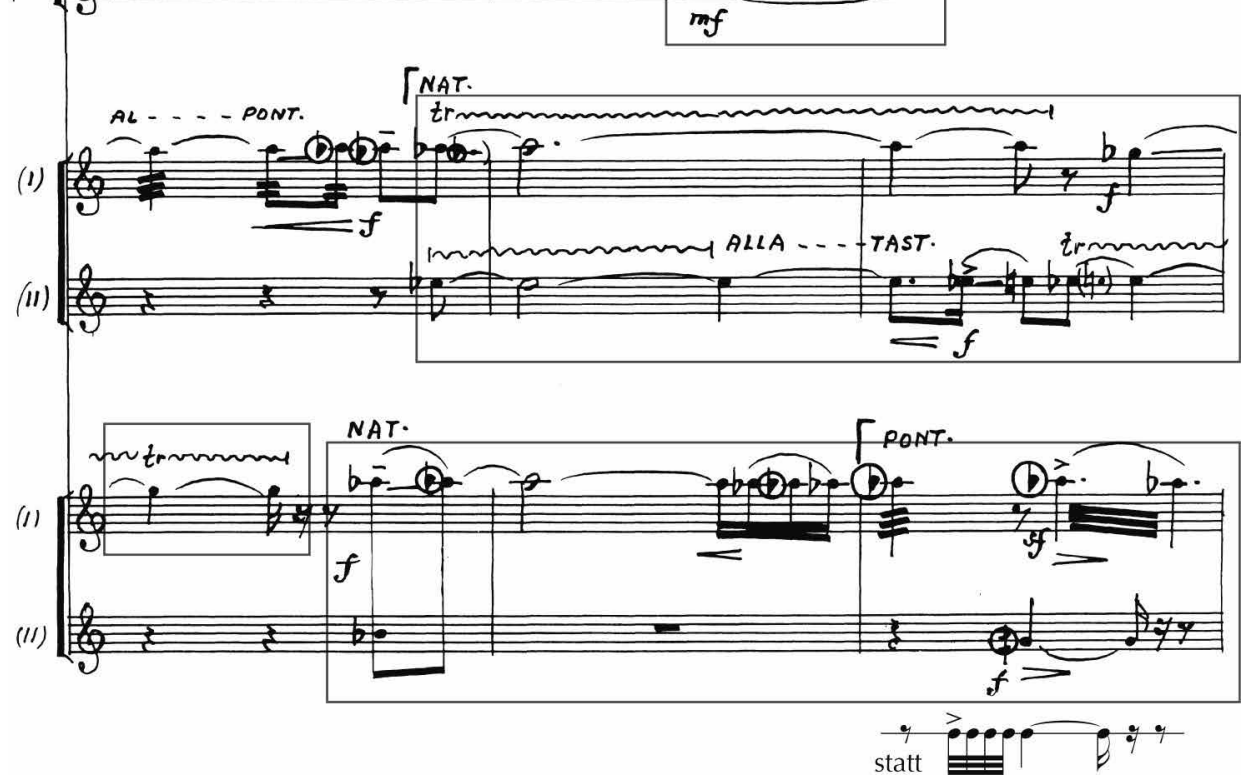